\title{
LAS ÉGLOGAS DE JUAN DE LA ENCINA. ESTUDIO BIBLIOGRÁFICO DE EDICIONES ANTIGUAS
}

\author{
Humberto LóPEZ MORALES \\ Universidad de Puerto Rico
}

A D. Rafael Lapesa, mi maestro, en su nonagésimo segundo aniversario.

\section{INTRODUCCIÓN}

Hasta donde sabemos, la producción dramática de Juan de la Encina consta de catorce piezas. Las primeras ocho aparecieron en la editio princeps del Cancionero, publicada en Salamanca en 1496, hace ahora poco más de quinientos años:

I. Égloga de Navidad,

II. Segunda égloga de Navidad,

III. Égloga de la passión de nuestro Redentor,

IV. Representación de Cristo,

V. Égloga de la noche postrera de Carnal,

VI. Segunda égloga de la noche postrera de Carnal,

VII. Égloga en recuesta de unos amores, y

VIII. Égloga de los pastores que se tornan del palacio ${ }^{1}$.

${ }^{1}$ Los títulos dados a las diversas piezas de Encina son, en su mayoría, parcialmente arbitrarios, puesto que ni el autor ni los impresores antiguos se encargaron de bautizarlas a todas. Ello explica que los actuales editores y los críticos difieran, a veces significativamente, en los títulos que manejan. En ocasiones se toman de la pequeña introducción que acompaña a estas obras, y que en ningún caso constituyen su título, como parece creer Luisa de Aliprandini, en el 'Estudio preliminar' a su edición del Triunfo del Amor y de la Égloga de Plácida y Vitoriano, Madrid, Ediciones Akal, 1995; en otras ocasiones, se prefiere dar relieve a un suceso del argumento o al nombre de sus personajes principales. No faltan los casos en que se opte por el título que aparece en alguna de las ediciones sueltas.

$R F E$, LXXX, 2000, $1 .^{\circ}-2 .^{\circ}$, págs. 89-128 
Se reimprimieron en el mismo orden en todas las ediciones antiguas: Sevilla, 1501; Burgos, 1505; Salamanca, 1507 y 1509, y Zaragoza, 1516. Otras dos obras:

\section{IX. Égloga de las grandes lluvias, y \\ X. Triunfo del amor}

fueron publicadas por primera vez en la edición de 1507, y dos más:

\section{XII. Égloga de Fileno y Zambardo, y \\ XIII. Auto del repelón,}

en la de 1509. Sus églogas XI (Égloga de Cristino y Febea) y XIV (Égloga de Plácida y Vitoriano) no llegaron nunca a las páginas del Cancionero, pero vieron la luz pública en ediciones sueltas ${ }^{2}$.

De esta nómina del teatro del salmantino se excluye la llamada Égloga interlocutoria, que le fuera atribuida injustificadamente ${ }^{3}$, pero se incluye, en

\footnotetext{
${ }^{2}$ La numeración que doy a las piezas responde al orden en que fueron impresas, no en el que se compusieron; la única excepción la constituye la égloga XI, para la que no tenemos ninguna información confiable. Esta decisión obedece a que lo relacionado con la cronología de la producción dramática enciniana es todavía asunto controvertido. Cf. José Caso González, "Cronología de las primeras obras de Juan de la Encina", Archivum, 4, 1953, págs. 362-372, y Juan Carlos Temprano, "Cronología de las ocho primeras églogas de Juan del Encina", Hispanic Review, 43, 1975, págs. 141-151. Los editores modernos de su teatro, por su parte, ofrecen diversos ordenamientos. Humberto López Morales, Églogas de Juan del Enzina, Madrid, Escelicer, 1963, y Églogas completas de Juan del Enzina, New York, Las Americas Publishing Co., 1968, trabaja con el que aquí reproducimos, mientras que Rosalie Gimeno, Teatro [de Juan del Encina], vol. 1, Madrid, Itsmo, 1975; vol. 2, Madrid, Alhambra, 1977; Ana María Rambaldo, Obras completas, vol. 4, Madrid, Espasa-Calpe, 1983, y Miguel Ángel Pérez Priego, Teatro completo [de Juan del Encina], Madrid, Cátedra, 1991, adoptan otros, todos ellos razonados en sus respectivas introducciones. Lo que parece ser seguro en este caso es que Encina había compuesto el material que aparece en la primera edición de su Cancionero entre sus 14 y sus 25 años de edad. Sus otras églogas, excepción hecha de la última, fueron escritas antes de que viajara a Italia por primera vez, cuando contaba con unos 30 años. Ya en Roma, en 1513, compuso la de Plácida y Vitoriano. No volvió a ocuparse del teatro.

3 Pedro Salvá y Mallén, en el Catálogo de la Biblioteca de Salvá, Valencia, Imprenta de Ferrer de Orga, 1872, fue quien describió por primera vez un ejemplar de esta pieza (I, 434) y quien, además, aunque con leves reservas, la atribuyó a Encina. Años más tarde, el texto fue encontrado y publicado por Urban Cronan, "Égloga interlocutoria", Review Hispanique, XXXVI, 1916, págs. 475-488, precedida de una corta introducción en la que indica, apoyado en Salvá, que el descubrimiento de este texto es un nuevo aporte a la dramática del salmantino. También Ralph E. House, "A study of Encina and the Égloga interlocutoria", Romanic Review, VII, 1916, págs. 458-469, afirma nuevamente la paternidad de Encina sobre esta égloga. Sin embargo, después del análisis métrico comparativo realizado por S. Griswold Morley, "Strophes in the Spanish drama before Lope", Homenaje a Menéndez Pidal, vol. I, Madrid, Librería y Casa editorial Hernando, S.A., 1925, especialmente la página 508, las dudas se disiparon. Ante conclusiones tan contundentes, la crítica ha retirado esta pieza de la nómina dramática de nuestro autor. Vid, también, Laurel H. Turk, Juan del Encina and the Spanish Renaisance, tesis doctoral inédita, Stanford University, 1933, págs. 267-268, y Humberto López Morales, Tradición y creación en los orígenes del teatro castellano, Madrid, Ediciones Alcalá, 1968, pág. 214, nota.
} 
cambio, el Auto del repelón, cuya paternidad le fue negada en una ocasión, aunque sin mayor fundamento ${ }^{4}$.

Una edición de finales del siglo XV y cinco ediciones tempranas del XVI, todo en un corto período de veinte años, más una serie de ediciones sueltas, casi todas sin datación pero de la misma época, dan idea de la popularidad alcanzada entonces por Encina, y no solo de su teatro ${ }^{5}$.

Sus obras dramáticas, sin embargo, no tuvieron la misma suerte en épocas posteriores. Poco a poco aumenta el silencio en torno a ellas, al tiempo que se producen solo algunas menciones apresuradas del salmantino; los ejemplares del Cancionero y de las sueltas comienzan a ser raros y la información bibliográfica, precaria.

En 1530, quizás pocos días después de la muerte de Encina en León ${ }^{6}$, aparecen anotadas en el Registrum librorum de Fernando Colón tres églogas suyas $^{7}$, pero ningún ejemplar del Cancionero, ni siquiera de la segunda edición,

${ }^{4}$ Para esta atrevida hipótesis, no respaldada por nadie, cf. Oliver T. Myers, "Juan del Encina and the Auto del repelón", Hispanic Review, XXXII, 1964, págs. 189-201.

${ }^{5}$ Se ha sugerido que quizás algunas de sus piezas dramáticas hayan sido impresas con anterioridad a 1496; la sugerencia se basa en las palabras del mismo Encina, primero, en la dedicatoria del Cancionero a los Duques de Alba, en la que da como una de las primeras razones de su publicación, que "andauan ya tan corrompidas y usurpadas algunas obrezillas mías que como mensageras auía embiado adelante, que ya no mías, mas agenas se podían llamar" (fol. vi r/v), y después, en la introducción a la primera égloga, en la que afirma que "...sacaría la copilación de todas sus obras porque se las usurpauan y corrompían" (fol. ciij r). Aunque Encina no especifica más, es de suponer que se tratase de su producción lírica. Son pocos los testimonios que hoy conocemos de ediciones sueltas de las églogas, y todos ellos son del siglo XVI.

${ }^{6}$ Encina debió de morir a finales de 1529 o en los primeros días de 1530 , pues el 14 de enero de este año se leía su testamento. Cf. Eloy Díaz Jiménez, Juan del Encina en León, Madrid, Fortanet, 1909. Más información sobre la biografía de Encina en el trabajo del propio Díaz Jiménez, "En torno a Juan del Encina", Revista de Segunda Enseñanza, V, 1927, págs. 398-401, en el estudio de Manuel Cañete, "Noticias que pueden servir para averiguar el verdadero apellido de Juan del Encina, poeta dramático español del siglo Xv", Revista Hispano Americana, 1, 1881, págs. 355-364, los de Rafael Mitjana, Sobre Juan del Encina músico y poeta (Nuevos datos para la biografia), Málaga, Tipografía Las Noticias, 1895, y "Nuevos documentos relativos a Juan del Encina", RFE, I, 1914, págs. 273-288 (recogidos ambos en sus Estudios sobre algunos músicos españoles del siglo XVI, Madrid, Sucesores de Hernando, 1918, págs. 5-36 y 37-51, respectivamente), el de Ricardo Espinosa Maeso, "Nuevos datos biográficos de Juan del Encina", BRAE, VIII, 1921, págs. 640-656, y el de Ernesto Giménez Caballero, "Hipótesis a un problema de Juan del Encina", RFE, XIV, 1927, págs. 59-69. Un buen resumen de la mayoría de los datos ofrecidos por estos autores puede verse en el "Prólogo" que Emilio Cotarelo escribió para la primera de las ediciones facsimilares hechas por la Real Academia Española (Madrid, Tipografia de la Revista de Archivos, Bibliotecas y Museos, 1928), especialmente en las páginas 7-20. La segunda edición facsímil reproduce también el "Prólogo" de Cotarelo (Madrid, Arco/Libros, 1989). Con posterioridad a estos trabajos clásicos, la bibliografia enciniana en general y biográfica en particular ha aumentado algo, aunque relativamente poco.

${ }^{7}$ Las églogas XII (Égloga de Juan del Enzina de 3 pastores) y XIV (Égloga de Plácida y Vitoriano) se encuentran consignadas en el Regestrum B, en el que se fueron anotando las obras que Hernando Colón compró hasta 1522, más unas pocas adquiridas hacia 1529-1530; Cf. el Catalogue of the Library of Ferdinand Colombus, reproduced in facsimile from the unique 
que había sido impresa en la misma Sevilla. En el primer tercio del siglo siguiente, Thomás Tamayo de Vargas menciona el Cancionero y la Tribagia, acompañados de una parca noticia bibliográfica ${ }^{8}$, que copió Nicolás Antonio en su totalidad, con un añadido desafortunado ${ }^{9}$. En el siglo XvIII, Gregorio Mayans y Siscar nos habla de dos ediciones del Cancionero, la de 1496, uno de cuyos ejemplares poseyó en su juventud, y otra, zaragozana, de 1512, de quien nadie más ha visto rastro ${ }^{10}$. En 1790, Jacques Charles Brunet, después de consultar más de trescientos catálogos bibliográficos para la elaboración de su Dictionaire, no encuentra obras de Encina en ninguno de ellos ${ }^{11}$.

Con Fray Francisco Méndez se inauguran los trabajos de historia tipográfica peninsular ${ }^{12}$. A partir de aquí ya suelen encontrarse algunas noticias

\footnotetext{
manuscript in the Colombine Library of Seville, by Archer M. Huntington, New York, 1905, números 3.851 y 4.044. La égloga X (Representatio amoris), aparece en el $A B C$ darium $B$, luego fue comprada en fecha tardía, quizás entre 1535 y 1536. cf. la edición facsimilar del Abecedarium $B$ y Supplementum, Madrid, Fúndación MAPFRE América, Sevilla, Cabildo de la Catedral, 1992, Col. 913, número 12.224. Los tres ejemplares citados, más otros 16.000 libros, han desaparecido de la colección debido al saqueo constante de cuatro siglos de que fue víctima la Biblioteca Colombina. Cf. Francisco Vindel, Los bibliófilos y sus bibliotecas desde la introducción de la imprenta en España, Madrid [Imprenta Góngora], 1934. Para los fondos actuales de la biblioteca, vid, Servando Arboli Faraudo, Biblioteca Colombina. Catálogo de sus impresos, Sevilla, E. Rasco, 1888, y más actualizado y útil para la investigación, el Catálogo concordado de la Biblioteca de Hernando Colón, que debemos a la infatigable labor del Dr. Klaus Wagner, y que pronto verá la luz en CD-Rom.

${ }^{8} \mathrm{La}$ obra de Tamayo de Vargas, compuesta alrededor de 1624 , es la primera referencia bibliográfica que conozco sobre la obra de Encina. El manuscrito de la Biblioteca Nacional de Madrid (MS. 9.753) trae una parca noticia del Cancionero: "J. de la Encina. Cancionero e/ otras cosas en verso a los Reyes Cathólicos. Cf. la Iunta de libros. La maior que España ha visto en su lengua hasta el año de C/. / C. XXIV, por Thomás Tamaio de Vargas, Chronista de su Mgestad, II Parte. El otro manuscrito consultado, el de la Universidad de Oviedo (MS. 88), repite la noticia, apenas sin variantes. Existieron otros manuscritos, como el que vio Nicolás Antonio en la Biblioteca Barberina de Roma (Cf. Bibliotheca Hispana Nova, Matriti, Ibarra, MDCCLXXXIII, II, 315) y el de la biblioteca particular de Roque Vidal. Si la Iunta de libros fue publicada como afirma Alejo Vanegas en su Primera parte de las diferencias de libros que ay en el Universo (Toledo, 1540) es asunto no comprobado hasta la fecha; los bibliógrafos modernos no han podido dar con ejemplares impresos. Cf. Homero Serís, Bibliografia de la literatura hispánica, I, Madrid, Consejo Superior de Investigaciones Científicas, 1965, números 947, 948. La Hispaniae Bibliotheca de Andreas Schottus (Francofuorti, Claudium Valentinorum, 1608), no menciona a Encina, como era de esperar, puesto que este catálogo solo se ocupa de autores que escribieron en latín.

${ }^{9}$ Nicolás Antonio repite: “... Extat quoque: Cancionero, con otras cosas en verso, a los Reyes Católicos. Ms. in Flio vidit D. Tomas Tamajus"; creyó que el Cancionero era obra manuscrita. Cf. Bibliotheca Hispana Nova, I, 684.

${ }^{10}$ Cf. infra, nota 49.

${ }_{11}$ Dictionaire bibliographique et critique des livres rares, précieux, singuliers, curieux et estimés et recherchés... avec leur valeur... Avequels on a ajoute des observations \& des notes pour faciliter la connaissance exacte \& certaine des éditions originales... suivi d'un Essai de bibliographie, Paris, Cailleau et Fils, MDCCXC.

${ }_{12}$ Typographía Española o Historia de la introducción y progresos del arte de la imprenta en España, Madrid, Ibarra, 1796; la segunda edición, corregida y adicionada por D. Dionisio Hidalgo, que es la que manejo, fue publicada en Madrid, Imprenta de las Escuelas Pías, 1861.
} 
y referencias en los mayores trabajos europeos de este tipo, así como en índices, inventarios, catálogos y colecciones. Pero ya para entonces los libros de Encina eran difíciles de encontrar, aun en España. Como muy raro aparece el Cancionero en un Ýndice de principios del $\mathrm{XIX}^{13}$.

Después del catálogo de Leandro Fernández de Moratín ${ }^{14} \mathrm{y}$, sobre todo, de los trabajos de Bartolomé José Gallardo ${ }^{15}$ - los más notables de su siglo- la información bibliográfica sobre el salmantino cambia de signo. Moratín conoció cuatro ediciones del Cancionero, y Gallardo, al dar noticia de la de 1507, a través del ejemplar de la Biblioteca Real de Madrid, aumentó a cinco el número de las ediciones conocidas. Con la publicación del Catálogo de Pedro Salvá y Mallén se siguieron llenando muchos vacíos, pero aun así la información bibliográfica sobre Encina continuaba siendo insuficiente. Desde entonces, los trabajos de Gallardo y de Salvá proporcionaron todos los datos que aparecen en los estudios de la primera mitad de este siglo $^{16}$.

La mayoría de los autores que se ocupaban entonces de la obra de Encina, o conocían las ediciones antiguas solo por referencia o, en el mejor de los casos, trabajaban con algún ejemplar específico, mientras que para los demás tomaban, si acaso, información subsidiaria de fuentes poco solventes ${ }^{17}$. El que los datos bibliográficos de la obra de Encina se encontraran dispersos e incompletos dio pie a las notables confusiones que se ad-

13 Ýndice alfabético de comedias, tragedias y demás piezas del Teatro Español formado por Joaquín Arteaga, 1820. (MS. 14.698 de la Biblioteca Nacional de Madrid); en uno de sus apéndices de raros, dice: "Cancionero de Juan de la Encina, en folio". Ya es algo. Unos años antes, Raymundo Diosdado Caballero, De prima typographiae hispanicae aetate specimen, Romae, Antonium Fulgonium, 1793, la primera bibliografia de incunables españoles, solo consignaba de nuestro autor, los Disparates trobados (no. 179); hay edición bilingüe latinoespañola: Breve examen acerca de los primeros tiempos del arte tipográfico en España, Versión española de D. Vicente Fontán, Madrid, Oficina Tipográfica del Hospicio, 1865.

${ }^{14}$ Orígenes del teatro español con una reseña histórica sobre el teatro español en el siglo XVIII y principios del XIX, Paris, Garnier Hermanos, [s.a.].

${ }^{15}$ Ensayo de una biblioteca española de libros raros y curiosos, formado con los apuntamientos de... Coordinados y aumentados por D. M. R. Zarco del Valle y D. J. Sancho Rayón, Vol. II, Madrid, Imprenta y estereotipia de M. Rivadeneyra, 1866.

${ }^{16}$ Cf. el estudio preliminar de la edición de Alfredo Álvarez de la Villa de El Aucto del repelón, Paris, Librería Paul Ollendorff, [1910?], y sobre todo, el influyente prólogo de Emilio Cotarelo a las ediciones facsimilares del Cancionero de 1496, ya citadas.

17 Por ejemplo, los casos de Juan Nicolás Böhl de Faber, Teatro español anterior a Lope de Vega, Hamburgo, 1832, que trabajó con un ejemplar de 1505, de Ferdinand Joseph Wolf, Studien zur Geschichte der spanischen und portugiesischen Nationalliteratur, Berlin, 1859, que solo conoció el ejemplar de Viena de 1509 (He tenido acceso únicamente a la versión española, Historia de las literaturas castellana y portuguesa, Traducción del alemán por Miguel de Unamuno, con notas y adiciones de Marcelino Menéndez y Pelayo, Madrid, Est. tipog. Agustín Avrial, S.A.) y de Pascual de Gayangos, que trabajó partiendo de un ejemplar de la edición de 1509 , para citar solo a autores antiguos, pero la lista podría llevarse hasta nuestros días con entera facilidad. 
vierten en la crítica y en la bibliografía misma: Adolf Friedrich Graf von Schack habla de una edición del Cancionero anterior a 1496 ${ }^{18}$; Alfredo Álvarez de la Villa menciona una de $1519^{19}$; Ronald Williams habla de otra de $1498^{20}$; James P. Crawford afirma que el Cancionero se imprimió no menos de ocho veces entre 1496 y $1516^{21}$; Emilio Cotarelo y Mori piensa que el ejemplar de la Biblioteca Nacional de Madrid, catalogado como de 1501 , pertenece a la edición de Burgos de $1505^{22}$. No hay que sorprenderse de esto, si las propias bibliotecas consolidan errores de mucha importancia: la Bibliothèque Nationale de Paris afirma en su catálogo que un ejemplar suyo de la edición zaragozana de 1516 es de la edición salmantina de $1507^{23}$, y el catálogo de la Biblioteca Real de Madrid nos dice que su ejemplar de 1507, único conocido hoy de esta edición, se publicó en Burgos en $1505^{24}$.

Aunque más recientemente algunos yerros han sido corregidos y se ha logrado ofrecer información más abundante, el teatro de Juan de la Encina sigue a la espera de un estudio bibliográfico de carácter monográfico. Es el que me propongo ofrecer al lector en las páginas que siguen.

\section{EDICIONES DEL CANCIONERO}

\subsection{Salamanca, $1496^{25}$}

Portada: Cancionero de las obras| de Juan del Enzina.

Formato: Fol. Signatura de los pliegos: [ ] $]^{2} a-s^{6} t-v^{4} ; 2$ h., 116 f., L. gót.

\footnotetext{
${ }^{18}$ No me ha sido posible ver el original alemán. Cf. la Historia de la literatura y del arte dramático en España, Traducida directamente del alemán por E. Mier, Madrid, Imprenta y Fundición de M. Mello, 1885, vol. I, págs. 117-118.

${ }^{19}$ El Aucto del repelón, ya citado, págs. 146, aunque parece ser errata.

20 The staging of plays in the Spanish peninsula prior to 1555, Iowa, Iowa Studies in Spanish Language and Literature, 5, 1935, pág. 23.

${ }^{21}$ The Spanish pastoral drama, Philadelphia, University of Pennsylvania Publications, 4, 1915, pág. 20

${ }^{22}$ En el "Prólogo" a la edición facsímil del Cancionero, ya citada, pág. 4.

23 Vid. el Catalogue général des livres imprimés de la Bibliothèque Nationale, vol. XLVII Paris, Imprimerie Nationale, 1897, 394; trabajo con la reproducción offset preparada por la Imp. Joseph Floch, en 1967. D. Daniel Devoto me comunicó en su día que los ejemplares del Catalogue para uso de la casa habían sido corregidos a su pedido hacía varios años.

${ }^{24}$ Dato erróneo que recoge, por ejemplo, José Simón Díaz en su Bibliografia de la literatura hispánica, vol. III, Madrid, Consejo Superior de Investigaciones Científicas, 1965, no. 4658.

${ }_{25}$ Vid. Georg Wolfgang Panzer, Annales typographici ab artis inventae origine ad annum MD (ad annum MDXXXVI continuati), Norimbergae, 1793-1803, 120; Jacques Charles Brunet, Manuel du libraire et de l'amateur de livres [1809], pero cito por la tercera edición, Paris, Crapelet, 1820, II, pág. 972; Ludwig Friedrich Theodor Hain, Repertorium bibliographicum in quo libri omnes ab arte typographica inventa usque ad annum MD, voluminis I, Pars II,
} 
Contenido: Portada, Tabla, texto en prosa y verso, estos a dos y tres columnas. Las representaciones comienzan en el folio ciij:

fol. ciij $r$ Representación en la noche de navidad a donde se introduzen dos pastores; y el vno entró primero en la sala adonde el duque y duquesa de alua estauan y llegó a presentar en nombre de Juan del enzina vna obra de la mesma fiesta endereçada a la duquesa mostrándose muy dichoso porque le avían ya recebido por suyo; y el otro entró después y començóse a razonar con él en nombre de los detratores y maldizientes.

fol. ciiij $r$ Otra en la mesma noche adonde se introduzen cuatro pastores en nombre de los cuatro evangelistas que hablan de la natividad de nuestro saluador.

fol. $c v v$ Otra a la passión de nuestro redentor adonde se introduzen dos hermitaños y vna muger llamada verónica que hablan de su preciosa passión y muerte; y vn ángel que les vino a consolar con esperança de la resureción.

fol. cvij $v$ Otra de la representación de cristo adonde se introduzen joseph aharimatía y la madalena y los dos dicípulos que yvan al castillo

J. G. Cottae Stuttgartiae et Jul Renouard Lutetiae Parisiorum, MDCCCXXVII, no. 6594; Moratín, Orígenes, pág. 79; Méndez, Typographía, no. 15; Gallardo, Catálogo, vol. III, col. 821, no. 2069, que escribe erróneamente que la edición consta de 196 folios (error que siguen Álvarez, Repelón, pág. 23, nota, y Brunet, Supplément a Manuel de libraire et de l'amateur de livres, vol. I, Paris, Librairie Firmin Didot Frères, Fils et Cie, 1870, 442); Alejandro Vidal y Díez, Memoria histórica de la Universidad de Salamanca, Salamanca, Imprenta de Oliva y Hernando, 1869, pág. 399; Salvá, Catálogo, no. 231, sigue a Méndez y añade "consta de dos hojas preliminares y cxvj folios. Durán se equivoca al suponer que la fecha es de 1497"; Escudero, Tipografia, 113; Konrad Haebler, Bibliografia ibérica del siglo XV. Enumeración de todos los libros impresos en España y Portugal hasta el año de 1500, La Haya, Martinus Nijhoff-Leipzig: Karl W. Hiersemann, 1904, no. 240; Johan Georg Theodor Graësse, Trésor de livres rares et précieux, au Nouveau Dictionnaire bibliographique, [1859-1869, pero cito por] vol. II, Berlin, Altmann, 1922, 473, que sigue a Méndez; Gesamtkatalog der Wiegendrucke. Herausgegeben von der Kommission für den Gesemtkatalog der Wiegendrucke, Leipzig, 1925-1938, número 9301; Francisco Vindel, Manual gráfico-descriptivo del bibliófilo hispano-americano (1475-1850), Madrid, Imprenta Góngora, 1930-1934, no. 3.334, y El arte tipográfico en España durante el siglo XV, vol. II (Salamanca, Zamora, Coria y Reino de Galicia), Madrid, Ministerio de Asuntos Exteriores, 1945-1951; Palau, Manual, V, pág. 51; Luisa Cuesta Gutiérrez, La imprenta en Salamanca. Avance del estudio de la tipografia salmantina (1480-1044), Salamanca, Diputación Provincial, 1960, pág. 93; José Simón Díaz, Bibliografia, III, 4656; Charles B. Faulhaber, Bibliography of Old Spanish Texts, Third edition compiled by CBF, Ángel Gómez Moreno, David MacKenzie, John J. Nitti y Brian Dutton, Madison, The Hispanic Seminary of Medieval Studies, 1984, pág. 79, no. 1039; Catálogo general de incunables en bibliotecas españolas, Coordinado y dirigido por Francisco García Craviotto, Madrid, Ministerio de Cultura, 1989, número 2276. Información sobre los impresores de esta editio princeps, en Haebler, Tipografia ibérica del siglo XV. Reproducción en facsimile de todos los caracteres tipográficos empleados en España y Portugal hasta el año de 1500, La Haya, Martinus Nijhoff-Leipzig: Karl W. Hiersemann, 1902, págs. 57-58. 
de emaús, que hablan de la resurreción y vn ángel que les acrecentó ell alegría.

fol. cjx $r$ Otra en la noche postrera de carnal adonde se introduzen cuatro pastores mostrando gran pesar y tristura porque se sonava que el duque de alva, su señor, se avía de partir a la guerra de francia.

fol. $c x v$ Otra en la mesma noche y por los mesmos pastores comiendo $\mathrm{y}$ beviendo y festejando mucho aquella fiesta.

fol. $c x j v$ Otra en requesta de vnos amores adonde se introduze vn escudero y vn pastor y vna pastorcica requestada del vno y del otro sobre quál la ternía por amiga.

fol. cxiij $r$ Otra adonde se introduzen los mesmos de arriba y otra pastora que era esposa de aquel pastor, $y$ todos juntamente dexando de ser pastores se tornaron del palacio.

Colofón: Fue impresso en Salamanca A veynte días| del mes de Julio de Mil. cccc. xcvj. años.

Ejemplares:

\section{Biblioteca del Real Monasterio de El Escorial, 33-Y-1026}

Falta todo el cuaderno p, con los folios correspondientes, del 85 al 90 . Falta, además, el folio 84, último del pliego o. En los folios conservados no hay errores de paginación, que está en romanos en letra minúscula en el borde superior derecho de los folios, con excepción de los folios 31,32 y 36 , que han sido impresos con minúscula, pero en tipos mayores y van en medio del borde superior. Este último folio $\mathrm{v}$, en blanco. El material que contenían los siete folios que faltan está consignado en la Tabla, aunque, como es sabido, esta no es exhaustiva.

En la parte superior de la portada hay algunas signaturas antiguas, una de ellas tachada. Debajo del título, a tinta, se lee la siguiente nota: 'Es muy raro y apreciable', y más abajo, también en letra cursiva pero mayor: 'R.

\footnotetext{
${ }^{26}$ Dio cuenta de este ejemplar por primera vez el padre Benigno Fernández, en sus "Incunables españoles en la Biblioteca de El Escorial", publicado en varias entregas de la $R e$ vista Agustiniana, LV (1901)-XC (1912). Más tarde volvió a registrarlo Teodoro Alonso Turienzo, "Índice de incunables de la Real Biblioteca de El Escorial y Biblioteca de la Comunidad de PP. Agustinos", La Ciudad de Dios, 187, 1974, págs. 646-668. Ver también el Catálogo General de Incunables en Bibliotecas Españolas, Coordinado y dirigido por Francisco García Graviotto, vol. I, Madrid, Dirección General del Libro y Biblioteca, 1989-1990, no. 2276. Álvarez, Repelón, pág. 23, menciona también el ejemplar de la Real Academia Española; Palau, Manual, V, pág. 51, menciona los ejemplares de la Real Academia Española y de Évora. Vindel, en su Manual gráfico-descriptivo, vol. XII, no. 3.334, ofrece foto de la portada y del colofón de este ejemplar escurialense; también en El arte tipográfico en España durante el siglo $X V$, Madrid, 1948, número 65.
} 
Biblioteca de S. Lorenzo'. En el margen derecho del primer folio de la Tabla hay una nota manuscrita con letra y tinta diferentes a las otras que dice: 'La égloga de Plácido [sic] y Vitoriano deeste autor está vedada'.

El ejemplar está encuadernado en piel castaña; lomo con cinco gruesos nervios sin tejuelo, ni grabados, ni adornos. Las tapas tienen dos marcos de tres líneas paralelas, el interno con adornos en las puntas y en el medio, todo grabado en madera. En la encuadernación han sido incluidas dos hojas de respeto delante y dos al final. Los bordes conservan restos de dorado y de letras: [J]? ENZINA; hay también un número 10 pintado con tinta negra en las partes superior e inferior del canto interno.

2. Biblioteca Pública y Arquivo Distrital de Évora, Incunábulos $221^{27}$

Faltan cinco folios: $81,82,109,110$ y 111; el folio 87 está en blanco. El material que contenían estos folios está consignado en la Tabla. Al faltar los folios 109-111, el ejemplar no tienen la égloga V, ni la VI, así como tampoco el comienzo de la VII, hasta el verso 16 , Dios lo sabe, ques testigo.

En el frontis, debajo del título, se encuentra el sello en tinta azul de la Biblioteca Pública de Évora; al margen derecho en letra manuscrita, en tinta: 'de| Ocampo'. En el folio anterior al frontis hay varias notas y marcas: en el borde superior en tinta, letra antigua: 'costó 22 t.' En el borde superior derecho, en lápiz violeta, 'N. 252', y debajo, una firma ilegible. También en lápiz, 'Haebler-240', y después, en color azul y subrayado, 'No. 221 '. En el resto del folio hay fragmentos de versos escritos en tinta y con letra antigua: A) Param... / Paz am..., B) La consideración/ quiero que sepas; C) La muy leal m...; D) ...deba mi... En el último folio v, que está en blanco, hay otros versos manuscritos: $Y$ anque estoy senor demi/ Si [?] pues q. la sin rezon/ de tu firme (esta palabra tachada, y sobre ella, antigua) condissión/ en lo que quieres en ti. El ejemplar está muy dañado en los últimos folios, que se encuentran apolillados y rotos. En el borde inferior la polilla ha mutilado levemente algunos versos; también hay algunas manchas de grasa, pero estas no entorpecen la lectura.

Está encuadernado en rústica con cartulina blanca. La encuadernación es pobre; lleva tejuelo castaño que dice, en letras mayúsculas doradas: INCUNÁBULOS/ 221.

\footnotetext{
${ }^{27}$ Cf. Antonio Joaquim Lopes da Silva Junior, Os reservados da Biblioteca Publica de Evora: Catálogo methódico, Coimbra, Imprensa da Universidade, 1905; Os incunábulos das Bibliotecas Portuguesas, vol. I. Lisboa, Secretaria de Estado da Cultura, Instituto da Biblioteca Nacional e do Livro, Inventário do Património Cultural Móvel, 1995, Número 668.
} 


\section{Biblioteca de la Real Academia Española, Madrid, I. $8^{28}$}

Los tres folios iniciales donde se encuentra el frontis y la Tabla son reproducciones facsimilares del ejemplar de El Escorial. Lo mismo los últimos cinco folios del cuaderno 1; el folio lxxxi, primero de este cuaderno, está pegado sobre otro papel de igual tamaño de los folios. El resto del cuaderno es copia fotográfica hecha sobre papel antiguo, pero posterior al siglo XVI, como demuestra su marca ${ }^{29}$. De esta forma se creó artificialmente un ejemplar completo.

No hay errores en la foliación, aunque la guillotina del encuadernador ha hecho desaparecer el número de los folios xv, xvi, xix, xx, xxii, liv y lxv. El xxii ha sido añadido en tinta. Quedan mutilados los números de los folios xxiii, $\mathrm{xxx}$, xxxi, xlix, lxix, lxxiv, lxxii, lxxvii, lxxviii y cxi. Las páginas del ejemplar han sido numeradas nuevamente a lápiz, quizás antes de desencuadernarlo para la primera edición facsimilar que preparó la Real Academia en 1928. Después del folio cxvi, último del Cancionero, vienen otros cuatro - A[i], Aii, Aiii y [Aiiii] — con la Tragedia trobada, desde el título hasta el verso que viendo tal cosa confian del mundo. Este texto de la Tragedia, que se unió aquí al Cancionero por obra de la encuadernación, fue publicado en Salamanca, $c$. de 1497; el ejemplar de la Academia está incompleto, pero en este caso no se hizo ningún intento de completar la obra fotografiando los dos folios que faltan.

El ejemplar está lujosamente encuadernado en piel.

\section{Bayerische Staatsbibliothek, München, $2 .^{\circ}$ Inc. c.a. $3323^{30}$}

Falta todo el cuaderno k, con los folios correspondientes, del 54 al 69 , en los que no hay material dramático.

\footnotetext{
${ }^{28}$ Barrera, Catálogo, pág. 130. Aunque no lo indica, se refiere al ejemplar de la Academia Española, que es el único de los conocidos que trae al final, por obra del encuadernador, la Tragedia Trobada; solo esta circunstancia pudo hacer decir a de la Barrera que la edición "contiene 9 representaciones." Cf. el Catálogo General de Incunables en las Bibliotecas Españolas, ya citado, vol. I, no. 2276.

${ }^{29}$ El papel utilizado para esta primera edición de Salamanca lleva la marca de la mano extendida (Cf. Charles-Moïse Briquet, Les filigranes. Dictionnaire des marques de papier dès leur apparition vers 1282 jusqu'en 1600, Deuxième edition, Leipzig, Verlag von Karl W. Hiersemann, 1923). La marca del papel utilizado para sustituir los folios perdidos del ejemplar de la Academia no figura en el diccionario de Briquet; es una especie de columna de varios cuerpos bastante elaborada que sirve de base a una cruz. No ha sido posible encontrar en los archivos y biblioteca de la Academia ninguna información sobre la preparación de la primera edición facsimilar de este ejemplar, que fue la que provocó el 'arreglo' del incunable académico. Que yo se$\mathrm{pa}$, nadie hasta ahora había reparado en la falsificación fotográfica de estos folios. Vid. Cotarelo, "Prólogo", pág. 3, que sólo conocía estos dos ejemplares: el académico y el de El Escorial.

${ }^{30}$ Haebler, Bibliografia, 240, describe la edición por este ejemplar alemán, aunque menciona el de El Escorial y el de la Real Academia Española. Vindel, Arte, II, 65, sigue la descripción de Haebler, pero cita también el ejemplar de Evora. Cf. Bayerische Staatsbibliothek Inkunabelkatalog, BSB-Ink, Vol. 2, Wiesbaden, Dr. Ludwig Reichert Verlag, 1991, pág. 364, no. E-54.
} 


\section{Bibliotecha Trivulzina, Milano, TRIV. INC B 64}

El ejemplar está incompleto. Le faltan los folios i-ii y lxxiii-cii, en los que no hay material dramático. Carece de ex libris y de notas manuscritas, con la excepción de 'le segnature, omesse dallo stampatore: ' $n$ ' alla carta $\mathrm{s} 1$, 'o' alla carta $\mathrm{t} 1$, 'p' alla carta $\mathrm{v1}$ '31.

Perteneció a la biblioteca de la familia Trivulzio, pasando a la de la Comune di Milano en 1935.

\subsection{Sevilla, $1501^{32}$}

Portada: Cancionero/ las obras de ju/ an del enzina.

Formato: Fol. Signatura de los pliegos: []$^{2} a^{6} b-o^{8} ; 2$ h., 110 f., L. gót.

Contenido: Portada, Tabla, texto en prosa y en verso, estos a dos y tres columnas. Las representaciones comienzan en el folio xcij r:

fol. $x c i j r$ Representación en la noche de nauidad a donde se introduzen dos pastores, y el vno entró primero en la sala a donde el duque y duquesa de alua estauan y llegó a presentar en nombre de Juan d'l enzina vna obra de la mesma fiesta endereçada a la duquesa mostrándose muy dichoso porque le auían recebido por suyo; y el otro entró después y començóse a razonar con él en nombre de los detratores y maldizientes.

fol. $x$ ciij $v$ Otra en la mesma noche a donde se introduzen quatro pastores en nombre d'los quatro euangelistas que hablan d'la natiuidad de nuestro saluador.

\footnotetext{
${ }^{31} \mathrm{Cf}$. el Indice Generale degli incunaboli delle bibliotheche d'Italia, A cura del Centro Nazionale d'Informazioni Bibliographiche, vol. II, Roma, La Libreria dello Stato, MCMXIVIII, no. 3673. El Dr. Giovanni M. Piazza, Director de la Biblioteca, ha tenido la amabilidad de revisar para mí algunas cuestiones concretas de este valioso ejemplar.

${ }^{32}$ En la Bibliotheca Grenvilliana, III, London, H.J. Payne, H. Foss y W.B. Rye, 1848, págs. 182-183, se dudaba de la existencia de esta edición, consignada ya por Brunet, Manuel, II, pág. 972, por F. Bouterwich, Geschichte der spanischen Poesie und Beredsamkeit, Göttingen, 1804; vol. III de Geschichte der Poesie und Beredsamkeit seit dem Ende des dreizehnten Jahrhunderts, y por Fried Adolf Ebert, Allgemeines bibliographisches Lexicon, Leipzig, Brockhaus, 1821-1830. La dieron por segura: Panzer, Annales, VIII, 1; Barrera, Catálogo, 130; Salvá, Catálogo, 231, sigue a Brunet; Escudero, Tipografia, pág. 113, parece que no vio ningún ejemplar, pues anota: "citada en Böhl de Faber"; Álvarez, Repelón, pág. 29, nota; Graësse, Trésor, II, 473; Palau, Manual, V, pág. 51, que sigue a Brunet; Joaquín Hazañas y la Rúa, La imprenta en Sevilla: noticias inéditas de sus impresores desde la introducción del arte tipográfico en esa ciudad hasta el siglo XIX, vol. I, Sevilla, Diputación Provincial, 19451949, pág. 55; Simón, Bibliografia, III, 4657; Frederick John Norton, Printing in Spain (1501-1520), Cambridge, Cambridge University Press, 1966, pág. 8, y A descriptive catalogue of printing in Spain and Portugal 1501-1520, Cambridge-London-New York-Melbourne, Cambridge University Press, 1978, no. 717. Información sobre los impresores, en Haebler, Tipografia, págs. 47-49 y Geschichte des spanischen Frühdruckes in Stammbaümen, Leipzig, Karl W. Hiersemann, 1923, págs. 362-380. Para los impresos del siglo xvI, cf. los Repertorios bibliográficos de impresos del siglo XVI (Españoles, portugueses, hispanoamericanos), de Juan Delgado Casado y Julián Martín Abad, Madrid, Arco/Libros, 1993.
} 
fol. $x c v$ r Otra a la passión de nuestro redentor a donde se introduzen dos hermitaños y vna muger llamada verónica, que hablan de su preciosa passión y muerte, y vn ángel que les vino a consolar con esperança de la resureción. fol. $x$ cviij $r$ Otra de la resureción de cristo a donde se introduzen joseph aharimatía y la madalena y los dos dicípulos que yuan al castillo de emaús, que hablan de la resureción, y vn ángel que les acrecentó ell alegría.

fol. $x$ cix $v$ Otra en la noche postrera de carnal a donde se introduzen quatro pastores mostrando gran pesar y tristura porque se sonaua que el duque de alua, su señor, se auía de partir a la guerra de francia.

fol. cj $r$ Otra en la mesma noche y por los mesmos pastores comiendo y biuiendo [sic] y festejando mucho aquella fiesta.

fol. cij $v$ Otra en requesta de vnos amores adonde se introduze vn escudero y vn pastor y vna pastorcica requestada del vno y del otro sobre quál la ternía por amiga.

fol. ciiij $v$ Otra adonde se introduzen los mesmos de arriba y otra pastora que era esposa de aquel pastor y todos juntamente dexando de ser pastores se tornaron del palacio.

Colofón, cviii: Fue empremida esta presente obra en la muy noble $\tau$ muy leal cibdad de Seuilla,| por Juanes [sic] pegnicer de nurenberga, y Magno herbst de fils, alemanes, por manda| do de los honrrados mercaderes Guido d'leazaris y Lazaro de gazanis, compañeros,| la qual se acabó a xvj días de Enero en el año del Señor, Mill y quinientos y vno. Sigue un escudo ${ }^{33}$.

Ejemplares:

\section{Erzog-August-Bibliothek, Wolfenbüttel ${ }^{34}$}

Los folios 75 y 99 están repetidos. Es el único ejemplar completo de los conocidos de 1501. Está limpio y cuidado; solo pueden encontrarse algunos subrayados a tinta en la introducción de la Égloga II. En la portada, sobre

33 Vid. Francisco Vindel, Escudos y marcas tipográficas de los impresores en España durante el siglo XV (1485-1500), Madrid, Imprenta Torrent, 1935, págs. 17-18.

${ }^{34}$ Cf. C. P. Schönemann, Zweites und drittes Hundert Merkwürdigkeiten der Herzoglichen Bibliothek zu Wolfenbüttel, Hannover, 1852, no. 255. Cañete, "Prohemio", pág. xi, dice: ... hay un precioso ejemplar de ella [la edición sevillana de 1501] en la escogida Biblioteca del Gran Ducado de Wolfenbüttel: ejemplar del que poseo minuciosa descripción y el facsímile de las hojas primera y última", pero nunca, que sepamos, hizo pública esta información. Las cartas que escribiera el Dr. Berthmann a Cañete, se conservan en la Biblioteca de la Real Academia Española: MS. 314: [Cartas (2) en francés del Dr. Berthmann, bibliotecario de la Biblioteca Ducal de Wolfenbüttel, de 18 y 19 de marzo de 1864, que incluyen la descripción de un ejemplar del Cancionero de Juan del Encina, impreso en 1508 [sic] de dicha Biblioteca]. A. 1864, papel, $6 \mathrm{ff} ., 32 \times 20 \mathrm{~cm}$. Incluye copia de la portada, marca de agua y tablas [sic] del ejemplar de Wolfenbüttel, así como otros datos bibliográficos. El material conserva parte del envoltorio, consistente en dos cartones con datos de procedencia. Cf. el Catálogo de manuscritos de la Real Academia Española, Boletín de la Real Academia Española, Anejo L, Madrid, 1991, pág. 302. 
el título, el sello de la Biblioteca de Wolfenbüttel. En el último folio, gran escudo a toda página de los Reyes Católicos, con el yugo, las flechas y la leyenda Tanto monta.

\section{Biblioteca Nacional, Madrid, R-20172 35}

El ejemplar está incompleto; solo llega hasta el folio xciij, al v. 72 de la Égloga II, quel es el verbo diuino. El resto del material que figura en el índice está añadido a mano, más las Coplas en loor del Apóstol Sant Pedro, la Égloga IX y la X, hasta el v. 354, y al jurado.

En el borde superior del folio donde comienza la Tabla de las obras hay una nota manuscrita que dice: 'Este tomo se imprimió en Salamanca el año de 1496 como se prueba de otro igual y completo (sin ojas [sic] N 3) que hay en la librería del Sr. Martin [sic] de Madrid'. Más abajo, con otra letra, se lee: 'Está equivocado, véase el $\mathrm{v}^{0}$ de la hoja 17 manuscrita'. Lo cierto es que ambas notas son incorrectas. Un cotejo de este ejemplar mutilado con uno de 1496 delata que, a pesar de que el material es el mismo, hay diferencias en el cuerpo de la letra, en la caja de imprenta y en la distribución del texto en folios. Por otra parte, en la hoja a donde remite la segunda mano, el copista ha transcrito el colofón de la edición salmantina de 1507, de la que copia, como queda demostrado, no solo por el material que incluye, sino por una nota que se lee al principio de las hojas manuscritas: 'Copiado de la edición de Salamanca, 1507'. Otra mano añadió debajo de esta última nota: 'letra de Gallardo'. La primera página manuscrita lleva a lápiz un 27 en el ángulo superior derecho; es el total de las hojas manuscritas, pero estas no tienen numeración. $\mathrm{El}$ ejemplar carece de colofón, lo que ha dado pie a las conjeturas anteriores.

Está encuadernado en pergamino. En la parte superior del lomo, en tinta negra: OBRAS| DE| JVAN| DEL| ENZINA.

\subsection{Burgos, $1505^{36}$}

Portada: Cancionero de| todas las obras de| jua [sic] del enzina con o| tras añadidas.

Formato: Fol. Signatura de los pliegos: []$^{2} a^{6} b-m^{8} n^{6} ; 2$ h., 99 f., L. gót.

${ }^{35}$ Cotarelo, "Prólogo", pág. 4, asegura que "el que en los índices de la Biblioteca Nacional tiene esta fecha es un ejemplar incompleto de la edición de Burgos", es decir, de 1505. Un cotejo con el ejemplar de Wolfenbüttel demuestra cuán equivocado estaba Cotarelo en esta afirmación, pues este de la Biblioteca Nacional corresponde con aquel en tipos, composición y distribución del material.

${ }_{36}$ Barrera, Catálogo, 130; Gallardo, Ensayo, col. 823, no. 2070; Escudero, Tipografia, 113; Graësse, Trésor, II, 473; Palau, Manual, V, pág. 51-52, no. 79.573; Simón, Bibliografia, III, 4658; Norton, Printing, 64, 131, y Catalogue, no. 313. Sobre Andrés de Burgos, Cf. Haebler, Tipografia, 45 y Geschichte, págs. 336-342. 
Contenido: Portada, Tabla, texto en prosa y verso, este a dos y tres columnas. Las representaciones comienzan en el folio lxxxiiij v:

fol. lxxxiiij $v$ Representación en la noche de nauidad adonde se introduzen dos pastores, y el vno entró primero en la sala adonde el duque y duquesa de alua estauan, y llegó a presentar en nombre de Juan del enzina vna obra d'la mesma fiesta endereçada a la Duquesa mostrándose muy dichoso porque le auía recebido por suyo; y el otro entró después y començóse a razonar con él en nombre de los detratores y maldizientes.

fol. lxxxvj $r$ Otra en la mesma noche, adonde se introduzen quatro pastores en nombre d'los quatro euangelistas que hablan de la natiuidad de nuestro saluador.

fol. lxxxvij $v$ Otra a la passión de nuestro redentor adonde se introduzen dos hermitaños y vna muger llamada verónica que hablan de su preciosa passión y muerte; y vn ángel que les vino a consolar con esperança de la resurreción.

fol. lxxxix $v$ Otra de la resurreción de cristo adonde se introduzen Joseph aharimatía y la madalena y los dos dicípulos que yuan al castillo de emaús, que habla de la resurreción [sic], y vn ángel que les acrecentó ell alegría.

fol. $x c j r$ Otra en la noche postrera de carnal adonde se introuzen quatro pastores mostrando gran pesar y tristura porque se sonaba que el duque de alua, su señor, se auía d'partir a la guerra de francia.

fol. $x c i j \mathrm{r} / v$ Otra en la mesma noche y por los mesmos pastores comiendo y biuiendo [sic] y festejando mucho aquella fiesta.

fol. $x$ ciiij $r$ Otra en requesta de vnos amores adonde se introduze vn escudero, vn pastor y vna pastorcica requestada del vno y del otro sobre quál la ternía por amiga.

fol. $x c v r$ Repastemos el ganado.

fol. $x c v i j$ Gasajémonos de huzía.

fol. $x c v i i j$ [sic, fol. $x c v$ v] Otra adonde se introduzen los mesmos d'arriba y otra pastora que era esposa de aquel pastor, y todos juntamente dexando de ser pastores se tornaron del palacio.

fol. xcviij $v$ Ninguno cierre las puertas

fol. xcix v Coplas en loor del apóstol sant Pedro

Colofón: Fue empremida esta pre| sente obra en la muy noble| y muy leal cibdad de Burgos| por Andrés de Burgos por| mandado de los honrrados $\mid$ mercaderes Francisco Dada| Juan Thomás Fauario; la $\mid$ qual se acabó a xiij días de| febrero en el año del Señor| Mill y quinientos y cinco.

Le sigue un grabadito en forma rectangular. Tres ángeles sostienen un escudo con algunos símbolos de la pasión: la cruz, la corona de espinas y un gran corazón sangrante por la herida de la lanza, y atravesado por una 
cruz. Después del colofón sigue el texto de las Coplas en loor del apóstol sant Pedro y un DEO GRACIAS.

Ejemplares:

\section{Biblioteca Nacional, Madrid, R-2960 37}

El ejemplar tiene 1 hoja de respeto añadida en la encuadernación y otra manuscrita de índice. Hay un error en la paginación de este y de todos los ejemplares de la edición de 1505 que he revisado: del folio vj se pasa al ix, pero no falta material alguno entre estos folios. En la hoja añadida por el encuadernador hay varias dedicatorias antiguas del ejemplar. El índice manuscrito colocado al final está a dos columnas en letra que parece del siglo XIX; trae todas las composiciones del Cancionero en orden alfabético, comenzando por Acuerda desacordado y regresando de nuevo a la $a$ al final con Aquel nuevo tiempo sereno pasado.

En el borde superior de la portada (que tienen este y el borde derecho reforzado con otro papel más nuevo) hay una nota a lápiz de Gallardo: 'Las variantes de lápiz son las que arroja la última impresión de este Cansionero [sic], hecha en Zaragoza año de 1516'. Firmado: Gallardo. Debajo de la última línea del título está anotada la primera de estas diferencias: entre la palabra otras y añadidas, Gallardo añadió cosas nuevamente, según la lectura de 1516. Debajo de este añadido a lápiz, hacia el margen izquierdo hay una nota a tinta en dos renglones con letra diferente y muy anterior. La primera de estas líneas resulta ilegible; la segunda parece decir más unas hojas. Debajo y hacia el centro del folio hay un sello oval, acuñado en tinta azul en cuyo centro se lee: 'Adquirida [por el] Gobierno [en] 1863' y en la franja de alrededor: 'Librería del Excmo. Sr. D. AG. Durán, S.N.'

Aparte de que algunas variantes con el Cancionero zaragozano están anotadas a lápiz por Gallardo, una mano anterior numeró con tinta las églogas, usando romanos en mayúscula. También los villancicos colocados al final de las

${ }^{37}$ Salvá, Catálogo, no. 231; Brunet, Supplément, I, pág. 442, dice: “on n'en connaît qu'un seul exemplaire, et MM. Zarco del Valle et S. Rayón, qui le décrivent, en paraissent pas absolument convaincus qu'il soit bien complet", pero los editores de Gallardo trabajaron con este ejemplar que fue de Böhl de Faber [Vid. "Catálogo de los principales artículos que componían la selecta librería de D. J. Böhl de Faber perteneciente hoy a la Biblioteca Nacional de Madrid", BRAH, LXXXI (1922), 478-494, y LXXXII (1923), 67-94, 165-190 y 248-267; también, en edición aparte: $\mathrm{Ca}$ tálogo formado por D. Bartolomé José Gallardo de los principales artículos que componían la selecta librería de D. Juan Nicolás Böhl de Faber perteneciente el día a la Biblioteca Nacional de Madrid, enmendado y anotado por Cayetano Alberto de la Barrera, Tipografia de la Revista de Archivos, 1923], y después de Durán [Inventario de la librería que fue del Excmo. Sr. D. Agustín Durán comprada por el Gobierno de S. M. con destino a la Biblioteca Nacional, Madrid, Imprenta y estereotipia M. Rivadeneyra, 1865] antes de pasar a la Biblioteca Nacional de Madrid, y que está completo; Álvarez, Repelón, pág. 29, nota; Cotarelo, "Prólogo", págs. 4-5. 
églogas o intercalados en ellas van numerados, estos en arábigo y comenzando con el número 50 para seguir con la numeración de los otros villancicos del Cancionero, que hizo la misma persona; el 49 corresponde al villancico pastoril Dime, Juan, por tu salud. Hay dos notas marginales hechas por esta mano desconocida en los folios lxxxv y lxxxvj, donde se explica el sentido del texto.

El ejemplar está encuadernado en pasta valenciana, lomo estampado en oro con cinco nervios y entre ellos elegantes ánforas. Tejuelo rojo con letras doradas: CANCIONERO| DE JUAN DE| LA ENCINA.

\section{Biblioteca Nacional, Madrid, R-3880}

Faltan los folios 50, 62, 64, 65, 66, 68, 69, 80, 81 y 96. Se encuentra el mismo error de paginación que en el ejemplar R. 2960 de la Biblioteca Nacional de Madrid, pero no falta material entre esos folios. El ejemplar carece de portada y de Tabla. Al faltar el folio 96, la Égloga VIII ha quedado sin los versos 18, si, nunca medre tu greña, al 190, sea llugo a más tardar.

Hay una hoja que antecede en la encuadernación al primer cuaderno con varias notas y números manuscritos, algunos tachados, mucho de ello intrascendente. Una de las notas dice: "faltan en este libro las hojas 50, 64, $65,66,80,81$ y 96 , pero son más las que faltan, como se ha visto. Desconozco si esos tres folios fueron arrancados con posterioridad a la redacción de la nota o si el resultado se debió a un recuento defectuoso. Otra nota que se lee muy claramente, dice: 'Cajón 81 , Núm. 8'.

Está encuadernado en pasta valenciana, lomo con cinco nervios a cuyos márgenes se encuentran unas grecas doradas. Tejuelo rojo con letras doradas: OBRAS| DE| JUAN| DE LA| ENCINA ${ }^{38}$.

\section{Library of the Hispanic Society of America, New York ${ }^{39}$}

No faltan folios, aunque también se advierte el mismo error de paginación que el R-2960 de la Biblioteca Nacional de Madrid. No tienen indi-

\footnotetext{
${ }^{38} \mathrm{El}$ ejemplar procede de la Biblioteca Capitular de Toledo; todavía aparece formando parte de esa colección en el Catálogo de la librería del Cabildo Toledano, preparado por José María Octavio de Toledo, 2. ${ }^{a}$ Parte, Madrid, Tipografía de la Revista de Archivos, Bibliotecas y Museos, 1906, no. 182, pero había pasado a la Biblioteca Nacional de Madrid en 1869 , como resultado de la última de las desamortizaciones de ese siglo. Aunque con posterioridad parte de esos fondos fueron devueltos a su lugar de origen, este ejemplar del Cancionero se quedó en su nueva residencia madrileña.

39 Vid. Clara Louisa Penney, $A$ list of books printed before 1601 in the Library of the Hispanic Society of America compiled by CLP, Hispanic Notes and Monographs, Catalogue Series, New York, Hispanic Society of America, 1955, pág. 89; hay edición ampliada: Printed books 1468-1700 in the Hispanic Society of America. A listing by CLP [Glückstadt-Imp. At J. J. Augustin], 1965.
} 
cación de cuadernos ni de página en el $\mathrm{d}$ iiij ni en el $\mathrm{n}$ i, pero están los folios.

En el frontis de este ejemplar había una larga nota manuscrita en letra antigua, pero está hoy muy borrosa e ilegible. El ejemplar tiene algunos subrayados y notas marginales en español; también algunas manchas de tinta.

Ex libris de la Hispanic Society of America, la leyenda QVIEN-ESCRIBIÓ-ESTE-LIBRO-DEL-DIOS-PARAYSO-AMEN, y debajo un sello.

Está encuadernado en piel castaña; lomo con cinco nervios muy ornamentados con grabados de flores y arabescos en hierro dorado. Tejuelo rojo con letras doradas: OBRAS| DE JUA| [sic] DELA| ENCINA.

\subsection{Salamanca, 1507}

Portada: Cancionero de todas las obras/ de Juan del enzina con otras co/ sas nueuamente añadidas.

'En medio de la portada, escudo con las armas reales; corona encima y un águila explayada, la cabeza mirando a la derecha. En dos cuadros alargados hay a la derecha un rey coronado e hincado de rodillas y un anciano de pie a su lado, y a la izquierda, una reina coronada, de rodillas y una mujer al lado de pie; un dosel sobre cada uno de estos cuadros ${ }^{40}$.

Formato: Fol. Signatura de los pliegos: []$^{2} \mathrm{a}-1^{8} \mathrm{~m}^{10} ; 2 \mathrm{~h}$., 96 f., L. gót.

Contenido: Portada, Tabla, texto en prosa y verso; la prosa a dos columnas, el verso, a dos y tres. Las representaciones comienzan en el folio lxxvij v:

fol. lxxvij $v$ Égloga representada en la noche de la natiuidad d'nuestro saluador a donde se introduzen dos pastores, vno llamado juan $\tau$ otro Mateo. $\tau$ aquel que juan se llamaua entró primero en la sala a donde el duque $\tau$ duquesa estauan oyendo maytines $\tau$ en nombre de juan d'l enzina llegó a presentar cient coplas d'aquesta fiesta a la señora duquesa, $\tau$ el otro pastor llamado Mateo entró d'spués desto $\tau$ en nombre d'los detratores $\tau$ mal dizientes, començóse a razonar con él.

fol. lxxix [Égloga II].

fol. lxxx $v$ Representación a la muy bendita passión $\tau$ muerte de nuestro precioso redentor, adonde se itroduzen dos hermataños [sic], el vno viejo y el otro moço, razonándose como entre padre y hijo, camino d'l sancto sepulcro, $\tau$ estando ya delante del monumento allegóse a razonar con ellos

${ }^{40}$ Cotarelo, "Prólogo", pág. 5. Vid. Gallardo, Ensayo, col. 824, no. 2071; Palau, Manual, V, pág. 52, no. 79.574; Simón, Bibliografia, no. 4659; Norton, Catalogue, no. 552; Lorenzo Ruiz Fidalgo, La imprenta en Sevilla (1501-1600), Madrid, Arco/Libros, 1994, no. 61. 
vna muger llamada verónica, a quien cristo, quando le lleuauan a crucificar dexó imprimida la figura de su glorioso rostro en vn paño que ella le dio para se alimpiar del sudor $\tau$ sangre que yua corriendo. Va esso mesmo introduzido vn ángel que vino a contemplar en el monumento y les traxo consuelo y esperança de la sancta resurreción.

fol. lxxxij $v$ Representación a la santíssima resurreción d'cristo, adonde se itroduzen joseph $\tau$ la madalena y los dos discípulos que yuan al castillo de emaús, los quales eran cleofás y san lucas; y cada vno cuenta de qué manera le aparesció nuestro redentor. primero joseph comiença contemplando el sepulcro en que a cristo sepultó, y d'spués entró la madalena, y estándose razonando con él, entraron los otros dos discípulos. $\mathrm{Y}$ en fin vino vn ángel a ellos por les acrescentar ell alegría y la fe de la resurreción.

fol. lxxxiij $v$ Égloga representada en la noche postrera de carnal que dizen de antruejo o carnestollendas, adonde se introduzen cuatro pastores llamados beneyto y bras, pedruelo y lloriente. $\tau$ primero beneyto entró en la sala adonde el duque y duquesa estauan comiençó [sic] mucho a dolerse y a cuytarse porque se sonaua que el duque, su señor, se auía de partir a la guerra de francia [...].

fol. lxxxv $r$ Égloga representada la mesma noche de Antruejo o carnestollendas adonde se introduzen los mesmos pastores d'arriba, llamados beneyto y bras, lloriente y pedruelo. $\tau$ primero beneyto entró en la sala adonde el duque y duquesa estauan tendido en el suelo de gran reposo, començó a cenar, luego bras, que ya auía cenado, entró diziendo: carnal fuera. Mas importunado de beneyto tornó otra vez a cenar con él, estando cenando y razonándose sobre la venida de quaresma, entraron lloriente y pedruelo, y todos quatro juntamente, comiendo y cantando con mucho plazer, dieron fin a su festejar.

fol. lxxxvj $v$ Égloga representada en requesta de vnos amores adonde se introduze vna pastorcica llamada pascuala, que yendo cantando con su ganado, entró en la sala adonde el duque y duquesa estauan. Y luego después della entró vn pastor llamado mingo y començó a requerilla; e estando en su requesta llegó vn escudero, que tan bien preso de sus amores, requestando y altercando el vno con el otro se la sossacó y se tornó pastor por ella.

fol. lxxxviij $r$ Égloga representada por las mesmas personas que en la de arriba van introduzidas, que son: vn pastor que de antes era escudero, llamado gil, y pascuala y mingo, y su esposa menga, que de nueuo agora aquí se introduzen [...].

fol. $x$ cij $r$ Coplas en loor del apóstol sant pedro.

fol. $x$ ciiij $v$ Égloga trobada por Juan del enzina, representada la noche d'nauidad, en la qual [se introduze] a quatro pastores, juan, miguellejo, rodrigacho y antón llamados, que sobre los infortunios d'las grandes lluuias y 
la muerte d'un sacristán se razonauan. Vn ángel aparesce y el nascimiento del saluador les [sic] anunciando; ellos con diuersos dones a su visitación se aparejan.

fol. $x c v j r$ Representación por Juan d'l enzina ante el muy esclarescido y muy illustre príncipe don Juan, nuestro soberano señor [...].

Colofón: Fue esta presente obra empri| mida por Hans gysser, alemán d'| Silgenstat, en la muy noble $\tau$ leal| cibdad de Salamanca, la qual acabóse a v. de enero del año de| mill quinientos $\tau$ siete $^{41}$.

Registrum: La suma de toda esta obra desde| la primera letra fasta la fin. Todos $\mid$ son quadernos salvo la postrimera letra. $\mathrm{m}$. que es quinterno.

Ejemplares $^{42}$ :

\section{Biblioteca del Palacio Real, Madrid, I.B. $15^{43}$}

Faltan los folios 2, 74 y 79. En el vuelto de la portada comienza la Tabla, que llega hasta Glosas de motes, fol. lxvj. El fol. xix apenas quedó impreso; todo lo que es posible leer se reduce a: ron los antiguos la piedad de Merelo: mas mu/ cho... Hay un error de paginación: se repite el folio 65, pero el segundo de ellos corresponde realmente al 66; no falta material. Al faltar el folio 79, el ejemplar carece del final de la Égloga I, a partir del verso nunca tal amo se vio, y del principio de la II, hasta el verso para hijo de tal padre.

En la portada, debajo del título hay un pequeño adorno hecho a mano con tinta, y más hacia el borde inferior un sello en rojo de la Real Biblioteca. Algunos versos de la Égloga IX están tachados con tinta, y sobre otros, también tachados, aparecen versiones más del gusto de este censor poético desconocido. También el nombre de algunos personajes está tachado, a veces en un intento de corregir algunos errores de falta de concordancia entre personaje y parlamento. En el vuelto del folio 98 , que está en blanco, hay letras, palabras sueltas y otros entretenimientos caligráficos,

\footnotetext{
${ }^{41}$ Sobre Hans Giesser, cf. Haebler, Tipografia, pág. 87, y Geschichte, págs. 430-431.

${ }^{42}$ Cuesta, Salamanca, págs. 123-124; Simón, Bibliografia, III, 4659, menciona un ejemplar de la Bibliothèque Nationale de Paris (Rés.Yg. 13). Es un error de catalogación de esa biblioteca; se trata de un ejemplar de la edición zaragozana de 1516, como testimonia el colofón, que puede leerse en el folio xci vuelto; Norton, Printing, pág. 29.

${ }^{43}$ Gallardo, Ensayo, col. 824, no. 2071, es el primero en describir un ejemplar de la edición salmantina de 1507, y describe el que desde entonces parece ser ejemplar único, el de la Biblioteca Real de Madrid. También lo describen Salvá, Catálogo, no. 231; Brunet, Supplément, I, pág. 442, y Cotarelo, "Prólogo", pág. 5. Lo menciona Ảlvarez, Repelón, pág. 29, nota. En la Biblioteca del Palacio Real este valiosísimo ejemplar estaba catalogado como de Burgos de 1505; sin duda la confusión se debió a que el colofón no está al final, sino en el folio xci vuelto. Como de Burgos de 1505 aparece en Simón, Bibliografia, III, 4658.
} 
amén de variados dibujos (uno de ellos una cabeza masculina coronada) que llenan por completo la página.

En la contratapa delantera hay un elaboradísimo ex libris de D. D. d'Archambauls: un gran escudo dieciochesco con columnas, cortinas, peldaños, ángeles y un libro abierto, en el que se lee 'Affaires de Clergé'. En el escudo, la leyenda In armis leones. Al pie del escudo: 'A Sergem Soul Carmiti/ 1778'.

El ejemplar está encuadernado en pasta valenciana de múltiples colores donde resaltan el verde, el azul y el amarillo. Las puntas de las tapas son de piel castaña clara, y el lomo - liso y feo- de piel natural. No hay nervaturas ni tejuelo. En el borde inferior del lomo, un papel blanco enmarcado por dos líneas azules con la signatura. Los cantos conservan restos de dorados.

\subsection{Salamanca, $1509^{44}$}

Portada: Cancionero de todas las obras de Juan| del enzina con las coplas de zambardo $\tau$ con el auto del repelón en el qual se introduze $\mid$ dos pastores, piernicurto Joha para [sic] | con otras cosas nueuamente añadidas.

Orla y gran escudo de los Reyes Católicos con el yugo, las flechas y la leyenda Tanto monta; en lo más bajo del folio, el título.

Formato: Fol. Signatura de los pliegos: [ $]^{3}$ a-n ${ }^{8} ; 3$ h., 101 f., L. gót.

Contenido: Portada, Tabla, texto en prosa y verso, este a dos y tres columnas. Las representaciones comienzan en el folio lxxvij v:

fol. lxxvij $v$ Representación en la noche de nauidad adonde se introduzen dos pastores, $\tau$ el vno entró primero en la sala a donde el duque $\tau$ duquesa de alua estauan $\tau$ llegó a presentar en nombre de Juan del enzina vna obra de la mesma fiesta endereçada a la duquesa mostrándose muy dichoso porque le auían rescebido por suyo, $\tau$ el otro entró después començóse a razonar con él en nombre de los d'tratores $\tau$ maldizientes.

\footnotetext{
44 Panzer, Annales, 417; Moratín, Orígenes, pág. 79; Wolf, Studien, pág. 271; Barrera, Catálogo, pág. 131; Brunet, Manuel, II, pág. 972; Gallardo, Ensayo, col. 824, no. 2072; Salvá, Catálogo, 231; describe por "Adiciones y notas a Ticknor, Historia de la literatura española, II, pág. 528; Escudero, Tipografia, 113; Brunet, Supplément, I, 442; Álvarez, Repelón, pág. 31, nota; Graësse, Trésor, II, pág. 473; Palau, Manual, V, pág. 52, no. 79.575; Simón, Bibliografia, III, 4660; Cuesta, Salamanca, pág. 125; Norton, Printing, 29 y Catalogue, no. 560; Ruiz Fidalgo, Salamanca, no. 75. Álvarez menciona dos ejemplares, el de la Biblioteca Imperial de Viena (hoy Österreichische Nationalbibliothek) y el que fue de Gayangos (hoy en la Biblioteca Nacional de Madrid, R. 12645), y Simón, uno de la Biblioteca Nacional de Madrid y el de la British Library.
} 
fol. lxxix $r$ Otra en la mesma noche a donde se introduzen quatro pastores en nombre d'los euangelistas que hablan de la natiuidad d'nuestro saluador.

Fol. lxxx $v$ Otra a la passión de nuestro redentor a donde se introduzen dos hermitaños vna muger llamada verónica que hablan de su preciosa passión $\tau$ muerte; $\tau$ vn ángel que les vino a consolar con esperança de la resurreción.

fol. lxxxij $v$ Otra de la resurreción d'xpo a donde se introduzen Joseph aharimatía $\tau$ la madalena $\tau$ los dos discípulos que yuan al castillo de emaús, que hablan de la resurreción, vn ángel que les acrescentó el alegría.

fol. lxxxiij $v$ Otra en la noche postrera d'carnal a donde se introduzen quatro pastores mostrando gran pesar $\tau$ tristura porque se sonaua que el duque d'alua, su señor, se auía d'partir a la guerra de francia.

fol. lxxxv $r$ Otra en la mesma noche $\tau$ por los mesmos pastores comiendo $\tau$ biuiendo [sic] festejando mucho aquella fiesta.

Fol. lxxxvj $v$ Otra en requesta d'vnos amores a donde se introduze vn escudero $\tau$ vn pastor $\tau$ vna pastorcica requestada d'l vno $\tau$ d'l otro sobre quál la ternía por amiga.

fol. lxxvij v. Repastemos el ganado.

fol. lxxxvij v [sic. fol. lxxxix r] Gasajémonos de huzía.

fol. lxxxviij $r$ Otra a donde se introduzen los mesmos de arriba $\tau$ otra pastora que era esposa de aquel pastor $\tau$ todos juntamente dexando de ser pastores se tornaron del palacio.

fol. lxxxviij [sic. fol. xcj r] Ninguno cierre las puertas.

fol. lxxxviij Coplas en loor del apóstol san pedro.

fol. xciiij [sic. fol. xciij v] Otra égloga representada a la noche de nauidad. tilla.

fol. $x c v j$ [sic. fol. xcv r] Otra representación a don juan, príncipe de cas-

fol. xcviij [sic. fol. xcvij v] Otra égloga de tres pastores nueuamente trobada por Juan del enzina.

fol. $c j v$ E las coplas del repelón

Colofón: Fue esta presente obra empri| mida por Hans Gysser, alemán| de Silgenstat, en la muy noble $\tau$ leal cibdad de Salamanca, la| qual dicha obra se acabó a vij| del mes d' agosto del año $d$ mil| $\tau$ quinientos $\tau$ nueue años.

Ejemplares:

\section{Biblioteca Nacional, Madrid, R-2935}

Hay un error en la paginación: se repite el folio lxxiij; el segundo es realmente el lxxiij. No faltan folios; el ejemplar está completo. 
En el texto de las églogas hay algunos subrayados en tinta (en la $\mathrm{X}$ y en el Auto del repelón). También se encuentran unas notas manuscritas al margen del folio xcij en las Coplas del apóstol san pedro. Otras notas en el folio xcv, v; son sólo de una línea y están cortadas por la guillotina del encuadernador. Por lo que puede leerse, se trata de alusiones ajenas al texto mismo.

El ejemplar está encuadernado en pasta valenciana; lomo estampado en oro con cinco nervios y entre ellos flores y otros adornos. Tejuelo rojo con letras doradas: CANCIO [sic]| DE| JUAN| DEL| ENCINA. Ex libris de la Condesa de Campo de Alange.

\section{Library of the Hispanic Society of America, New York ${ }^{45}$}

El mismo error de paginación que el R-2935 de la Biblioteca Nacional de Madrid, pero aquí alguien ha añadido a lápiz una $\mathrm{j}$ lunga tras el lxxiij impreso. Hay notas manuscritas modernas en el Arte de trobar.

Ex libris de la Hispanic Society of America y la leyenda QUIEN-ESCRIBIO-ESTE-LIBRO-DEL-DIOS-PARAYSO-AMEN.

Está encuadernado en piel castellana oscura muy cuarteada; sencilla orla dorada alrededor de las tapas. Lomo con cinco nervios con líneas doradas a cada lado. Tejuelo rojo con letras doradas: CANCIONERO| DE TODAS| LAS OBRAS.

\section{British Museum, London, G. $11.367^{46}$}

El mismo error de paginación que en el R-2935 de la Biblioteca Nacional de Madrid. El ejemplar está muy bien conservado; los folios están limpísimos. Lujosamente encuadernado en piel roja sobre madera, orla dorada en los bordes de las tapas; en el centro, grabado en hierro dorado, el escudo de la Biblioteca Grenvilliana, en cuyo borde se lee: $\mathrm{T}^{\mathrm{t}} \mathrm{HON}^{\text {ble }} \mathrm{THO}^{\mathrm{s}}$ GRENVILLE. Lomo con seis nervios, profusamente ornamentado en dorado. Grabado en hierro dorado en el lomo: LAS| OBRAS| DE JUAN| DEL| ENZINA, y más abajo: SALAMANCA| MDIX. En el borde superior del lomo, sobre un papel verde: 11367.

\footnotetext{
${ }^{45}$ Penney, List, pág. 89.

${ }^{46}$ British Museum Catalogue of printed books, vol. XXIV, London, William Clowes and Sons, 1887, pág. 179; Henry Rhodes, Short-title Catalogue of books printed in Spain and of Spanish books printed elsewhere in Europe before 1601 now in the British Museum, London, Milford, 1921, y la versión moderna de Dennis E. Rhodes, Catalogue of books printed in Spain and Portugal and of Spanish books printed elsewere in Europe before 1601 now in the British Library, 2. ${ }^{\mathrm{a}}$ edición, London, The British Library, 1989, pág. 70.
} 


\section{Biblioteca Nacional de Madrid, R-12645}

La paginación es muy irregular: 1-16, 19-20, 18-23, 26-27, 25-40, 45$49,52-55,50-55,57-73,75-95,97-104$. Se encuentran repetidos los folios $19,20,26,27,52,53,54$ y 55 , pero estos folios no repiten todo el material, como se verá. El ejemplar, además, está incompleto: faltan los folios 17, 24, 40-45, 56, 74 y 96. Aparece el mismo error de paginación que en el ejemplar de la Biblioteca Nacional de Madrid R-2935.

El primer folio 19 repite el material del folio $\mathrm{xvj}$, $\mathrm{v}$, desde el verso De gran tiempo sin dudar. El material que corresponde al folio xvij del R. 2,935 y que empieza con el verso judith en la defensión está en la segunda estrofa de la segunda columna del primer folio xix de este ejemplar. El texto con el que empieza el folio xvij v está en la segunda estrofa de la segunda columna del primer folio xix de este ejemplar. Se han repetido seis estrofas y media. En la primera columna del primer folio xxvj se repite el Nunc dimittis, el Ave Maris stella y el Que terra ponthus del folio xxiij $v$ del R-2935. El folio xxvj v repite el material del folio xxiiij $r$ del R-2935. El primer folio xxvij $r$ del presente ejemplar repite el texto del folio xxiiij v de R-2935 con la diferencia de unos pocos versos. El primer folio xxvij $\mathrm{v}$ de este ejemplar repite el texto del folio xxv r del R-2935. Los folios xxvij y xxv del presente ejemplar tienen aproximadamente el mismo material: se repite el final del gloria, todo el Pater noster, el Ave Maria, el Credo y casi toda la Salve. El follio xlv empieza repitiendo el Triunfo de Fama que había empezado ya en el folio xl r, como el R-2935. El material de este ejemplar que fue de Gayangos, sigue desde aquí retrasado en comparación con el R-2935, pero no falta texto, salvo el de los folios que se han perdido, lo que denuncia una tirada diferente de la misma edición. El Triunfo de Fama termina: R-2935, folio xlij v; aquí, folio xlvij r. Obra (...) antes que le recibiessen por suyo, empieza en R-2935 en el folio xlij v; aquí, xliij v. Obra (...) después que le recibieron por suyo: R-2935, folio xliij v; aquí, xlviij r. Al magnifico Gutierre de Toledo: R-2935, folio xliiij v; aquí, xljx r. Esta obra a Gutierre de Toledo finaliza, en el presente ejemplar, con el verso y Crates y Antístenes y un gran Platón, al final del folio $\mathrm{xljx} \mathrm{v}$; faltan los últimos veintiocho versos de la composición, y todo lo que sigue hasta la novena estrofa del Almoneda. Los Disparates empiezan en R-2935 en el folio xlvij $r$ y en este ejemplar, en el folio lij r. El Juyzio de lo más cierto de la astrología, en R-2935, folio xlvij v; aquí, folio liiij v. (...) qué cosa era la corte : R-2935, folio xlviij v; aquí, folio liiij v. El prólogo al Triunfo del Amor: R-2935, folio xlix v; aquí, folio lv r. El Triunfo del Amor mismo: R-2935, folio 1 v; aquí, folio lv v. Como es- 
te ejemplar no tiene el folio lvj falta todo el material consignado en la Tabla. De igual manera, por faltar el folio lxxiij no se encuentran los villancicos Vencedores son tus ojos, Ojos garços ha la niña, Montesina era la garça, Madre, lo que no queréys, Dime, zagal, qué has avido, y Andá acá, pastor. Lo más importante a nuestro actual propósito es la falta del folio $\mathrm{xcvj}$, donde se encuentra parte del texto de la égloga X: desde el verso 108, simple, de poco saber, hasta el 293, tien comienço y no medio $^{47}$.

El ejemplar está encuadernado en piel; las tapas, adornadas con un marco de tres líneas paralelas grabadas en hierro dorado. Lomo cuajado con cinco nervios. Grabado en el lomo con letras doradas: CANCIONERO| DE| JOAN [sic]| DEL| ENZINA; en el borde inferior del lomo: SALAMANCA| MDIX.

\section{5. Österreichische Nationalbibliothek, Wien, $35 . N .3^{48}$}

Es un ejemplar completo, aunque con pocas y ligeras manchas de humedad. En el frontis, varias anotaciones manuscritas, casi todas ilegibles; sobre el escudo, a derecha e izquierda de la cabeza del águila, se lee 'De don| Carlos de| ?'. Hay anotaciones manuscritas esporádicas a lo largo del volumen: una muy larga e ilegible en la fotocopia con la que trabajo, en el fl. lxxx, otra más breve, en el lxxxij; en el nj v, se ha tachado el nombre de Pelayo, personaje que pronuncia los versos que empiezan con ora sigue tus antojos, y se ha escrito el de bras [sic], que es a quien el corrector supone que corresponde este parlamento. En el folio ciij v, se leen varias rúbricas, y antes del verso de discretos es aviso, que recita el estudiante del Auto del repelón, una mano ha escrito: 'don Bernardo de ?' El folio final está lleno de escritos, anotaciones y juegos caligráficos, muchos ilegibles, pero en todo caso, ajenos a la obra misma.

En la guarda final aparece en un recuadro la signatura *35.N.3; más abajo 'MENTEM ALIT ET EXCOLIT, seguido de un dibujo a plumilla, de líneas muy sencillas, con la fachada de la bibioteca vienesa. Bajo este grabado: K.K. HOFBIBLIOTHEK| ÖSTERR. NATIONALBIBLIOTHEK, y más abajo, en letras muy grandes, aparece repetida la signatura del volumen.

Encuadernación antigua, del siglo XVI, en pergamino.

\footnotetext{
${ }^{47}$ Cotarelo, "Prólogo", págs. 5-6, que se basa en este excepcional ejemplar para describir la edición, no da la menor cuenta de estas irregularidades.

${ }^{48}$ Debo a la amabilidad de la Dra. Anna Plattner la fotocopia íntegra de este texto y algunos detalles sobre el ejemplar.
} 


\subsection{Zaragoza, 1512}

No se conocen ejemplares ${ }^{49}$.

\subsection{Zaragoza, $1516^{50}$}

Portada: Cancionero de todas las| obras de Juan del enzina, con otras col sas nueuamente añadidas.

Gran escudo de los Reyes Católicos con el yugo, el haz de flechas y la leyenda Tanto monta. En lo más bajo del folio, el título.

Formato: Fol. Signatura de los pliegos: []$^{3} \mathrm{a}-1^{8} \mathrm{~m}^{10} ; 3 \mathrm{~h}$., $95 \mathrm{f}$., L. gót.

Contenido: Portada, Tabla, texto en prosa y verso, este a dos y tres columnas. Las representaciones comienzan en el folio LXXVII v:

Fol. LXXVII $v$ Representación en la noche d'nauidad. adonde se introduzen dos pastores, y el vno entró primero en la sala adonde el duque y la duquesa estauan, $\tau$ legó a presentar en nombre de Juan del enzina vna obra de la mesma fiesta endereçada a la duquesa, mostrándose muy dichoso porque le aían ya recebido por suyo; y el otro entró después $\tau$ començóse a razonar con él en nombre de los detratores $\tau$ maldizientes.

${ }^{49}$ La noticia de su existencia fue dada por primera vez en la Vida de Publio Virgilio Marron, con la noticia de sus obras traducidas al castellano, Valencia, 1778, p. 202. Se hicieron eco de ella, entre otros, Cayetano Alberto de la Barrera, Catálogo bibliográfico y biográfico del teatro antiguo español, desde sus origenes hasta mediados del siglo XVIII, Madrid, Imprenta y estereotipia de M. Rivadeneyra, 1860, pág. 131; Salvá, Catálogo, no. 213; Francisco Escudero Perosso, Tipografia hispalense, Anales bibliográficos de la ciudad de Sevilla, desde el establecimiento de la imprenta hasta finales del siglo XVII, Madrid, Est. tip. Sucesores de Rivadeneyra, 1894, pág. 113; Antonio Palau y Dulcet, Manual del librero hispano-americano, Barcelona, Librería Anticuaria, 1921-1927, pero manejo la segunda edición: Manual del librero hispanoamericano. Bibliografia general española e hispanoamericana desde la invención de la imprenta hasta nuestros tiempos con el valor comercial de los impresos descritos, vol. V, Barcelona, Librería Palau, 1951, pág. 52; Cotarelo, "Prólogo", pág. 6; Simón Díaz, Bibliografia, III, 4661, y Norton, Catalogue, no. 653. Sin embargo, ya Manuel Cañete, en el "Prohemio" al Teatro completo de Juan del Encina, Madrid, Est. y Tip. Sucesores de Rivadeneyra, 1893, pág. ix, recogía y hacía suya la sospecha de Gallardo, de que esta edición no había existido.

50 Brunet, Manuel, II, pág. 973, y Pierre Gustave Brunet, Nouvelles recherches, I, pág. 477; Moratín, Orígenes, pág. 79; Barrera, Catálogo, pág. 131; Gallardo, Ensayo, col. 845, 2030; Álvarez, Repelón, pág. 32, nota; Sánchez, Aragón, 59; Sánchez, Bibliografia, I, 76; Graësse, Trésor, II, pág. 473; Palau, Manual, V, pág. 52, no. 79.576; Cotarelo, "Prólogo", pág. 6; Francisco de Mello, Catálogo da biblioteca antiga que perteneceu ao Conde de Ficalho [Francisco de Mello] para venda em Leitao que terá início em 8 de abril de 1946, Lisboa: Arnaldo Henriques de Oliveira, 1946, 401; Vindel, Manuel, III, 870, con facsímil del frontis; Simón, Bibliografia, III, 4662; Norton, Printing, pág. 74, y Catalogue, no. 691. Sobre el impresor Coci, Cf. Haebler, Geschichte, págs. 311-312. Sánchez, Bibliografia, menciona el ejemplar que fue de Salvá (hoy en la Hispanic Society of America), el de la British Library y el de la Biblioteca Nacional de Madrid, que fue de Durán; Simón, Bibliografia, III, 4662, añade el de la Biblioteca Universitaria de Santiago de Compostela. 
Fol. $L X X I X r$ Otra en la mesma noche adonde se introduzen quatro pastores en nombre de los quatro euangelistas que hablan de la natiuidad de nuestro saluador.

Fol. $L X X X v$ Otra a la passión de nuestro redentor adonde se introduzen dos hermitaños $\tau$ vna muger llamada verónica que hablan de su preciosa passión $\tau$ muerte; $\tau$ vn ángel que les vino a consolar con esperança de la resurreción.

Fol. LXXXII v Otra de la resurreción de cristo adonde se introduzen Joseph aharimatía la magdalena $\tau$ los dos discípulos que yuan al castillo de Emaús, que hablan de la resurreción; $\tau$ vn ángel que les acrescentó el alegría.

Fol. LXXXIII $v$ Otra en la noche postrera de carnal, adonde se introduzen quatro pastores mostrando gran pesar tristesa porque se sonaua que el duque de alua, su señor, se auía de partir a la guerra d'francia.

Fol. LXXCV [sic. fol. LXXXV r] Otra en la mesma noche y por los mesmos pastores comiendo $\tau$ beuiendo $\tau$ festejando mucho aquella fiesta.

Fol. $L X X X V I v$ Otra en requesta de vnos amores, adonde se introduzen vn escudero vn pastor $\tau$ vna pastorcica requestada d'l vno $\tau$ del otro sobre quál se la ternía por su amiga.

Fol. $L X X X V I I v$ Repastemos el ganado.

Fol. $L X X X I X r$ Gasajémonos de huzía.

Fol. $L X X X I X r$ [sic. fol. LXXXVIII r] Otra adonde se introduzen los mesmos de arriba otra pastora que era esposa de aquel pastor $\tau$ todos juntamente dexando de ser pastores se tornaron de palacio.

Fol. XCI $r$ Ninguno cierre las puertas.

Fol. XCI $r$ Dos romances.

Fol. XCII $r$ Coplas en loor del apóstol san pedro.

Fol. XCIIII $v$ Otra égloga representada en la noche de nauidad.

Fol. XCVI $r$ Otra representación al nuestro muy esclarecido príncipe don Juan de castilla, del amor.

Colofón: Fue imprimido el presen| te libro llamado Cancionero| por Jorge Coci, en Çaragoça| Acabóse a xv días del mes| de deziembre. Año de mill $\tau \mid$ quinientos desiséys años.

Ejemplares:

\section{Biblioteca Nacional, Madrid, R-2040}

No hay errores de paginación; está en romanos con letra mayúscula, menos en los folios 9 y 16, que está con minúscula.

El ejemplar está encuadernado en holandesa, lomo negro sin nervios, pero muy adornado con dibujos simétricos grabados en hierro dorado. En el 
lomo, grabado también en dorado: CANCIONERO| DE| JUAN| DEL| ENZINA. En el borde inferior: $1516^{51}$.

\section{Biblioteca Nacional, Madrid, R-30777}

En este ejemplar, como en el de la Biblioteca Nacional de Madrid R-2040, los folios 9 y 16 están numerados en minúscula.

Está encuadernado en piel verde; las tapas decoradas con un marco de tres filetes dorados. Lomo cuajado con cinco nervios; cantos, contracantos y corte dorados. Impreso en el lomo: CANCIONERO| DE JUAN| DEL ENZINA, y más abajo ÇARAGOÇA| 1516. El ejemplar está muy recortado por la guillotina del encuadernador; la encuadernación está firmada: 'bounded by F. Bedford'.

\section{Biblioteca Nacional, Madrid, R-2969}

Falta todo el cuaderno g (los folios correspondientes son del 49 al 56). También aquí los folios 9 y 16 van numerados con minúscula. El folio XCVIII v, que está en blanco en todos los ejemplares, ha sido utilizado para copiar Contra los que dizen mal de mugeres, que falta en el texto impreso. La copia manuscrita de la composición sigue en una hoja añadida s.n.

En la portada, debajo del título, a tinta, hay una firma ilegible [Jullio Ganotro B?] y una nota que dice: 'Zaragoza 1516, vid. fol. 92'. Dentro del escudo de la portada hay un sello en tinta negra, pero muy borroso. Después del colofón, en el folio XCI $\mathrm{v}$ hay otra nota: 'Antes se imprimió en Burgos año de 1509 [sic] por Andrés de Burgos, y se acabó á 13 de Febrero: y antes en Salamanca año de 1496, por Junio'.

El ejemplar está encuadernado en pergamino. Su encuadernador recortó mucho los bordes del libro, que perteneció a una hermosa edición de amplios márgenes. Tejuelo en piel castaña clara con letras grabadas en hierro dorado: OBRAS $\mid$ DE JUAN $|\infty|$ D. ENCIN.

4. British Museum, London, G. $11.366^{52}$

El ejemplar está muy limpio y cuidado. En el borde superior del folio LXV hay una nota que dice: "misplaced" [?]. En una de las dos últimas hojas

\footnotetext{
${ }^{51}$ Esta es la encuardenación que tenía el ejemplar en la década del 60, cuando lo revisé; con posterioridad fue encuadernado de nuevo. Ahora lleva tapas duras cubiertas de pergamino blanqueado con orla dorada; lomo liso sin tejuelo, en el que se lee, con letras doradas, J. DEL ENZINA, y tras un filete pequeño, CANCIONERO.

${ }^{52}$ British Museum, vol. XXIV, pág. 179.
} 
puestas al final por el encuadernador, han pegado un dibujo hecho a plumilla. Es un escudo que tiene en uno de los cuadrantes los leones y los castillos, y en el centro las flores de lis de Francia. Todo el escudo cae delante de una gran águila bicéfala de alas extendidas; de la boca de la cabeza derecha sale la leyenda PIETATE ET ORNAT; de la de la izquierda, MAGNTVDINE ET [sic]. Bajo el escudo se lee: ESCVRIALF.

Pegada a una de las hojas de respeto que ha puesto el encuadernador hay una larga nota erudita: 'Enzina, Cancionero. fo. Saragossa. 1516.-date at p.-91-all the early editions of this work are rare. Antonii Bib. N. p. 684 describes the author born at 1446, but supposes this work only exist in M.SS. Caballero \& Santander 11.391 quote an edition of 1496 as the first, so does Panzer VII. $120 \& 417$ refers to one of 1509 . That of 1501 quoted by Bouterwich, p. $126 \&$ that of 1507 Bibliog. Univ: XIII. 176 seem to be of more doubful authority. See also Velázquez Origines [sic] 4. ${ }^{\circ}, 55$ 95. in Brunet's Supp. I, p. 477 he notes separately an edition in the Royal Library of Paris as "précieuse" of 98 leaves, of 23 columns no date with the arms of arragon [sic] on the first leaf, a blank on the reverse of the last leaf. By this minate description it is evident that the Copy which he quotes is this Copy of 1516, the date of which instead of being on the last leaf, p. 98 is to be found on the 91 page on the reverse, which was not noticed by Brunet or Salvá'.

This present edition corresponds with that of 1509 up to p. 97 where this edition ends, having however at p. 91 un Romance de un penado amador not in the edition of 1509."

El ejemplar está lujosamente encuadernado en piel verde sobre madera. Sobria orla dorada en los bordes de las tapas, y en el centro el escudo de la Biblioteca Grenvilliana, grabado en hierro dorado. Lomo con seis nervios; decoraciones simples y elegantes de marcos cuadrados entre los nervios. Grabado en el lomo: CANCIONERO| DI [sic] ENZINA, y más abajo: SARAGOSSA| MDXVI. En un pequeño tejuelo verde arriba: 11366.

\section{Library of the Hispanic Society of America, New York ${ }^{53}$}

También aquí los folios 9 y 16 van numerados en minúscula.

Ex libris de la Hispanic Society, y la leyenda QVIEN-ESCRIBIO-ESTELIBRO-DEL-DIOS-PARAYSO-AMEN. También está el ex libris del Marqués de Jerez de los Caballeros. En el vuelto de la primera hoja de la encuadernación hay dos números: 375, y más abajo, 742 (los números 7 no son europeos). También se leen las iniciales O. M. R. C.; la O, en tinta roja, las demás, en negro.

\footnotetext{
${ }^{53}$ Penney, List, pág. 89.
} 
Está encuadernado en piel negra; orla dorada con ángulos muy elaborados en las tapas. En el centro, también grabado en hierro dorado, el escudo de la Bibliothèque de Mello. Lomo cuajado con seis nervios. Grabado con letras doradas: CANCIONERO| DE TODAS| LAS OBRAS| DE JUAN| DEL ENZINA, y en el borde inferior: 1516| CARAGOÇA [sic].

\section{Library of The Hispanic Society of America, New York}

Es un ejemplar completo y muy cuidado, encuadernado de manera algo original ${ }^{54}$. Perteneció a Salvá, después a Ricardo Heredia, más tarde al profesor W. Y. Knapp, y finalmente a Archer Milton Huntington, quien lo donó a The Hispanic Society of America; todos sus dueños han dejado su huella en el ejemplar, a través de ex libris, leyendas y sellos ${ }^{55}$.

\section{Biblioteca Universitaria de Santiago de Compostela, 21.250}

Faltan los folios 93, 94, 96 y 97, por lo tanto, faltan los últimos versos de las Coplas en loor del apóstol san Pedro, a partir de en la fe pero tu lengua. Asimismo falta el principio de la Égloga IX: el folio 95 comienza con el verso 84 (y entrar en nouenta nueue). Al faltar los últimos dos folios, la Égloga $\mathrm{X}$ termina con el verso 173 (porque te tomas comigo).

En la cara interna de la portada hay varios papeles pegados de diversos tamaños. El más pequeño es una papeleta de signatura topográfica: $\mathrm{R} / 18$. Otra dice: 'Legado del Excmo. Sor $\mathrm{D}^{\mathrm{n}}$ Jacobo $\mathrm{M}^{\mathrm{a}}$ de Parga y Puga'. En otro papel se enumeran las ediciones del Cancionero: Salamanca 1496, Sevilla 1502 [sic], Burgos 1505, con las coplas del Zambardo [y el] auto del Repelon [sic], Zaragoza 1516. En el mismo papel, la mano que añadió arriba el dato de Gallardo puso corchetes a Zaragoza 1516, y añadió 'esta es'. Más abajo y en letra moderna, se ha copiado la descripción de Brunet, II, pág. 128.

El ejemplar está encuadernado en papel castaño con vetas azules. El lomo es de piel negra; los nervios, en bajo relieve, y a ambos bordes de cada uno, un filete dorado. Sobre el lomo, en letra gótica dorada, ENCINA, y debajo con mayúsculas, CANCIONERO. Casi en el borde inferior del lomo, tejuelo blanco que dice: EX BIBLIOTHECA| 21250| COMPOSTELLANA ${ }^{56}$.

\footnotetext{
54 "It is bound in faded orange-brown, straight-grained morocco, gilt tooling, moiré sink pastedowns and yellow head and tail bands, unsigned", según palabras literales de Miss Penney

${ }^{55}$ Vid. Salvá, Catálogo, 231; Catalogue de la Bibliothèque de M. Ricardo Heredia, Comte de Benahavis, vol. II, Paris, E. Paul L. Huard et Guillemin, 1891-1894.

56 Cf. José María de Bustamante y Urrutia, Catálogo de la Biblioteca Universitaria, II: Impresos del siglo XVI, Tomo primero: 1500-1569, Santiago de Compostela, Secretariado de Publicaciones, Universidad, 1946.
} 


\section{Biblioteca de Catalunya, Barcelona, Res. $425-4 .^{\circ 57}$}

Falta la indicación de cuaderno y folio en $\mathrm{m}^{4} \mathrm{y} \mathrm{m}^{5}$, pero están los folios. También los folios 9 y 16 van numerados en minúscula. Ejemplar muy cuidado. Ex libris de la Colección teatral barcelonesa 'Arturo Sedó', a la que perteneció el ejemplar hasta la muerte de su dueño (Vitrina A, estante 6). Bellísima encuadernación de Brugalla en piel repujada (1949). En el lomo, grabado: JUAN| DE LA ENCINA, y más abajo: ZARAGOZA| 1516.

\section{Bibliothèque Nationale, Paris, Rés. Yg. 13}

Está encuadernado elegantemente con las armas de Gaston d'Orleans, 'lo que significa que pertenece al núcleo inicial de la biblioteca de su sobrino Luis XVI, y que, por lo tanto, forma parte de la Bibliothèque Royal (hoy Nationale) desde el siglo XVII ${ }^{58}$.

\section{Biblioteca Nacional, Lisboa, Res. 1111}

Se trata de un fragmento de 21 folios. Tiene portada manuscrita moderna: Cancionero| de todas las obras de| Juan del Encinal con otras nuevamente añadidas| Caragoça [sic] a xv de deziembre de 1516.

Estos fragmentos comienzan con la Tabla, en el folio II, donde hay un sello de la Biblioteca Nacional de Lisboa. Sigue hasta el VI, después aparecen el IX y los X-XX. Continúa el texto en el folio LXXXI, en medio de la Égloga III, desde el verso Mi sentido bien alcança hasta por perdón, en las bocas del Hijo y de la Verónica respectivamente, este último verso en el LXXXII v. Sigue de inmediato la Égloga IV (Representacion a la . santissima resurrecion...) y después, la V (Égloga representada la noche postrera del carnal...). La primera estrofa está incompleta; solo tiene el primer verso, $O$ triste de mi, cuytado, y el séptimo, a beneyto del collado, con el que termina el texto de esta pieza, en la segunda columna del LXXXIII v.

La encuadenación es pobre, en cartón color crema, donde se lee: Enzina| Obras| FRAGM. INCOMP| Res 1111| BN Lisboa.

\footnotetext{
57 Montaner, Colección, pág. 45. En mayo de 1967, D. Antonio Rodríguez Moñino me informaba que un ejemplar muy incompleto del Cancionero de 1516 estaba en manos del librero Roque Vidal, quien lo anunciaba en su catálogo de 1944. El erudito bibliófilo sospechaba entonces que quizás fuera este el ejemplar de D. Arturo Sedó, pero no es así; el ejemplar que perteneció a la biblioteca de Sedó está completo. Información sobre el paso de esta biblioteca particular a la de Cataluña, en Ana Vázquez Estévez, Impresos dramáticos españoles de los siglos XVI y XVII en las bibliotecas de Barcelona. La transmisión teatral impresa, Kassel, Edition Reichenberger, 1995.

${ }^{58} \mathrm{El}$ Catalogue général des livres imprimés de la Bibliothèque Nationale, vol. XLVII, pág. 394 , ya se ha visto, la da como de 1507 .
} 


\section{Biblioteca Nacional, Lisboa, Res 253}

El volumen se abre con una hoja amarilla rallada manuscrita que dice: 'Res 253' en lápiz azul, y más abajo otra: 'Collecçao de 2 peças'. Continúa después: '1.Las CCC del poeta Juan de Mena [...] (Sevilla, 1517) y La Coronación (Sevilla, 1520). 2. Cancionero de todas las obras de Juan del Encina (Çaragoça, 1516, a xv deciembre). Falta no ultimo a fl. 91 onde estava a nota do lugar de imprensa, nome do impresor, data.) Jorge Coci. V. Brunet, s.v. Encina ou Enzina'.

El Cancionero, con foliación propia, está completo, a excepción del citado folio 91. En el frontis, sello de la Biblioteca Nacional de Lisboa. En lugar del folio perdido aparece una hoja amarilla rayada manuscrita, que dice: 'fl. XCI verso. Por Jorge Coci: en Caragoça [sic]. Acabóse| a xii dias del mes de deziembre| Año de mill. quinientos deziséys| años (1516)| (V. Brunet, s.v. Encina)| Falta este folio. El volumen termina abruptamente en el fl. XCVIII, en el verso ayudaros he yo luego de la égloga llamada Triunfo de amor. Hay una hoja de guarda al final.

El ejemplar está encuadernado en piel con sobrios grabados rectangulares, aunque en la parte superior el lomo está parcialmente desprendido. Quedan restos de manecillas metálicas. El lomo es moderno, de papel castaño, con la signatura Reservado| 253| B.N.L. en la parte inferior.

\section{Real Academia Española, Legado María Brey-Antonio Rodríguez Moñino, Madrid, R.M. 72}

El ejemplar no solo está completo, sino muy cuidado y limpio.

En la contraportada se le ha pegado un recorte de catálogo, que dice: '119. ENZINA (Juan de). Cancionero de todas las obras de Juan del Enzina: con otras cosas nuevamente añadidas... (in fine:) Saragosse, Jorge Coci, 1516: in folio gothique, demi-maroquin à graines longs, dos orné. 90.000 '. En párrafo aparte: 'Palau, V, 52. Belle et rare édition de ce Cancionero imprimé en gothique sur deux colonnes, avec sur le titre un grand blason gravé sur bois. Ce volume reaferme les Églogues de Juan de del [sic] Encina qui furent, dit-on, les premières représentations dramatiques en Espagne'. Más abajo, entre paréntesis, en letra manuscrita de Rodríguez Moñino: 'Librairie Georges Heilbron, Paris, Catalogue, núm. 5' En la hoja de guarda, en la esquina superior derecha, a lápiz, 'Vitrina 6. 72', que es la signatura de la biblioteca particular de Rodríguez Moñino. En el folio XCVIII v, que está en blanco, hay restos antiguos de letras y de palabras, que resultan ilegibles hoy.

El ejemplar está encuadernado en medio marroquín, con lomo y cantoneras en piel roja. Lomera con seis nervios y adornos dorados entre ellos. 
Entre el primero y el tercero, tejuelo que dice: JUAN| DEL ENZINA| [adorno] | CANCIO| NERO. En el borde inferior, tejuelo con la nueva signatura académica del Legado.

\section{The Houghton Library, The Harvard College University ${ }^{59}$}

El ejemplar está incompleto: faltan los folios LXXXIX y XCVIII, aunque el primero de ellos ha sido suplido por una copia facsimilar. Al final se han añadido los folios XCVII-CIIII, procedentes de la edición salmantina de 1509.

Lleva ex libris de Charles Stuard, barón de Rothesay y de James P. R. Lyell. Su último dueño, antes de pasar a la biblioteca de Harvard, fue Philip Hofer, de aquí lo de 'ejemplar Hofer', como lo conocieron los bibliógrafos hasta hace poco.

\section{EDICIONES SUELTAS}

Églogas V y VI. Égloga de la noche postrera de Carnal, Segunda égloga de la noche postrera de Carnal $^{60}$.

Portada: No tiene.

Formato: [4] h.-Sign.: $a^{4} .-4 .^{\circ}$ Cuarto. L. gót.

Contenido: Texto en prosa (las introducciones) y en verso, este a dos columnas. Égloga V; primer verso: $O$ triste de mí cuytado; último: quel es la paz verdadera. Égloga VI; primer verso: Carnal fuera carnal fuera; último: $y$ mañana ayunaremos.

Colofón: No tiene [Sevilla, Jacobo Cromberger, c. 1515?].

${ }^{59}$ Cf. Anne Anninger, Spanish and Portuguese 16th Century Books in the Department of Printing and Graphic Arts. A description of an Exhibition and a Bibliographical Catalogue of the Collection, Cambridge [MA], The Houghton Library, 1985, pág. 52, no. 47.

${ }^{60}$ Salvá, Catálogo, 1.228, con descripción del que fuera su ejemplar, hoy en la Bibliothèque Nationale de Paris; Catalogue général, vol. XXIV, pág. 395; Cotarelo, "Prólogo", pág. 22, que sigue fielmente a Salvá; Palau, V, pág. 52, no. 79.588; Simón, Bibliografia, III, 4.697; Norton, A descriptive Catalogue of printing in Spain and Portugal. 1501-1520, Cambridge, Cambridge University Press, 1978, no. 882; Brian Dutton, Catálogo/índice de la poesía cancioneril del siglo XV, Madison, 1982, 15* EJ; Faulhaber, Bibliography, pág. 217 , no. 2.623 . La impresión es del siglo XVI, y no anterior a 1496 , como sospechaban algunos autores. Norton, Catalogue, 881, y Clive Griffin, The Combergers of Seville: The history of a printing and merchant dynasty, Oxford, Clarendon Press, 1988, no. 146 (en la versión española, Los Cromberger. La historia de una imprenta en el siglo XVI en Sevilla y Méjico [sic], Madrid, Ediciones de Cultura Hispánica, 1991, el no. 146 está en la pág. 316), señalan que esta suelta fue impresa en Sevilla por Jacobo Comberger, hacia 1515 . 
Ejemplares:

1. Bibliothèque Nationale, Paris, Rés.Yg. 89

Ejemplar completo.

Égloga X. Triunfo del amor.

\section{A}

Portada: No tiene. La primera hoja comienza con la introducción: Égloga trobada por Juan del enzi| na. En la qual representa el amor de cómo andaua a tirar| en vna selua. Y de cómo salió vn pastor llamado Pelayo a dezille que porqué andaua a tirar en lugar deuedado. Y después có| mo lo hirió el amor. Y de cómo vino otro pastor llamado Bras a con $\mid$ solallo; otro pastor llamado Juanillo y vn escudero que llegó a ellos.

Formato: [4] h.-Sign.: $a^{4} .-4 .^{\circ}$ L. gót.

Contenido: Texto en prosa (la introducción) y en verso, este a dos columnas. Primer verso: Ninguno tenga osadia; último: ayudaros he yo luego. Al final, el villancico Ojos garços ha la niña.

Colofón: No tiene.

Ejemplares:

\section{Biblioteca Nacional, Madrid, R- $3655^{61}$}

Ejemplar completo. Encuadernado en piel; en las tapas, un grabado a bajo relieve; escudo de la BIBLIOTECA| DE SALVÁ. Lomo con cuatro nervios a cada lado de los cuales hay sobrios adornos. Sobre la piel del lomo, en letras doradas: ÉGLOGA| DE| ENZINA, y más abajo: S. L. NI A. En la encuadernación hay siete hojas de respeto.

$\mathrm{B}^{62}$

Portada: No tiene. La primera página comienza con la introducción: Égloga trobada por Juan del enzina en la qual representa el amor.

${ }^{61}$ Salvá, Catálogo, 1.228, a quien perteneció este ejemplar; Catalogue de la Bibliothèque de M. Ricardo Heredia, II, pág. 270, no. 2.311, "Bel exemplaire de Salvá"; Barrera, Catálogo, 722-723; Palau, V, pág. 52, no. 79.585; Cotarelo, "Prólogo", págs. 22-23; Simón, Bibliografia, III, 4.700; F. H. Norton y E. M. Wilson, Two Spanish verse chap-books: Romance de Amadís (c. 1515-19), Juyzio hallado y trobado (c. 1510). A facsimile edition with bibliographical and textual studies, Cambridge, Cambridge University Press, 1969, 29. Además de que al final trae el villancico Ojos garços ha la niña, hay notables diferencias entre el texto de esta suelta y el del Cancionero de 1509. En el Catalogue de la biblioteca de Heredia se dice que este ejemplar pertenece a una edición de "vers 1525", información que repite Palau, pero no se aducen razones para tal fechado. Hay edición facsímil en Autos, comedias y farsas de la Biblioteca Nacional, Madrid, Joyas bibliográficas, 1964, vol. II, págs. 1-8.

${ }^{62}$ Salvá, 1.228; Catalogue général, págs. 394-395; Cotarelo, 22-23, que sigue a Salvá; Simón Díaz, 4700. 
Formato: [4] h.-Sign.: $a^{4} .-4 .^{\circ}$ L. gót.

Contenido: Texto en prosa (la introducción) y en verso, este a dos columnas. Primer verso: Ninguno tenga osadía; último: ayudaros he yo luego. Al final de la égloga, el villancico Ojos garços ha la niña.

Colofón: No tiene [Burgos, Fadrique Biel de Basilea, c. 1515-1519].

Ejemplares:

\section{Bibliothèque Nationale, Paris. Rés. Yg. 87}

Ejemplar completo.

$\mathrm{C}$

El único ejemplar de esta edición está en la Biblioteca Pública Municipal de Oporto, y ha sido publicado facsimilarmente en $1976^{63}$.

D

Portada: No tiene. La primera página comienza con la introducción: Égloga trobada por Iuan d'l Enzina| En la qual representa el amor...

Formato: [4] h.-Sign. $a^{4} .-4 .^{\circ}$ L. gót.

Contenido: Texto en prosa (la introducción) y en verso a dos columnas. Primer verso: Ninguno tanga osadía; último: ayudar vos he luego. Al final de la égloga, el villancico Ojos garços ha la niña.

Colofón: No tiene [Sevilla, Jacobo Cromberger, c. 1510] ${ }^{64}$.

Ejemplares:

1. Biblioteca del Cigarral del Carmen, Toledo

Ejemplar completo, editado facsimilarmente en Toledo en 1999.

Égloga XI. Égloga de Cristino y Febea.

${ }^{63}$ Biblioteca Municipal de Oporto. Norton \& Wilson, Spanish chap-books, 29; Norton, Catalogue, 1132. Véase la reproducción facsimilar de este pliego, en Pliegos poéticos españoles de la Biblioteca Pública Municipal de Oporto, presentación de María Cruz García de Enterría, Madrid, 'Joyas bibliográficas', 1976, págs. 125-132.

${ }^{64}$ La obrita está en un volumen facticio del XVI, en el que se encuentra también la Tragicomedia de Calisto y Melibea (Zaragoza, Jorge Coci, 1507), la Estoria del noble cavallero el conde de Fernan Gonzalez con la muerte de los siete infantes de Lara (¿Toledo, Sucesor de Pedro Hagenbach, 1511?) y La leciones de Job en caso de amores de García Sánchez de Badajoz (¿Burgos, Fadrique Biel de Basilea, c. 1516?). Este volumen facticio fue descrito por H. C. Heaton, "A volumen of rare Sixteenth Century Spanish dramatic works", Romanic Review, 18, 1927, págs. 339-345. Vid. también Julián Martín Abad, "Otro volumen facticio de raros impresos españoles del siglo xvI", Pliegos de Bibliofilia, 4, 1998, págs. 8-9. Hay edición facsimilar en Un volumen facticio de raros post-incunables españoles, obra coordinada por Martín Abad, Toledo, Antonio Pareja Editor, 1999. 
Portada: No tiene. Encabezando la primera hoja: Égloga nueuamente trobada por Juan del enzil na a donde se introduze vn pastor que con otro se aconseja queriendo d'xar este mundo sus vanidades por| seruir a dios, el qual después d'auerse retraydo a ser hermitaño, el dios d'amor muy enojado porque sin sul licencia lo auía fecho, vna ninpha embía a le tentar d'tal suerte que forçado d'l amor d'xa los ábitos y la religión.

$\mathrm{Al}$ empezar la primera columna hay un grabado en madera con las figuras de Cristino, Justino y Febea, los protagonistas de esta pieza. El nombre de los interlocutores, sobre cada figura, menos el de Amor que va al final. Al grabado sigue el texto de la égloga.

Formato: Fol.; 2 h. sin numerar, L. gót.

Contenido: Texto en prosa (la introducción) y en verso, este a tres columnas. Primer verso: En buena hora estés, Justino; último: No me lo preguntes, no.

Colofón: No tiene.

\section{Ejemplares:}

\section{Biblioteca Menéndez Pelayo, Santander, R-III-A, $595^{65}$}

Ejemplar único y completo; dos folios, sin numerar. El tomito donde se encuentra esta égloga trae antes de ella el Romance de don gayferos que trata de cómo sacó a su espo/ sa que estaua en tierra de moros, y el Romance nueuamente hecho de Calisto y Meli/bea; los dos constan de dos hojas en folio cada uno. El encuadernador ha colocado hojas blancas entre cada obra.

${ }^{65}$ Salvá, Catálogo, 1.228; Francisco Asenjo Barbieri, "Adiciones" al "Prohemio" de Cañete, Teatro completo de Juan del Encina, ya citado, pág. LXV: Álvarez, Repelón, pág. 223, sigue a Asenjo Barbieri; Palau, V, pág. 52, no. 79.589; Cotarelo, "Prólogo", pág. 26, cita y describe por Salvá; Simón, Bibliografia, III, 4.698; Faulhaber, Bibliography, pág. 250, no. 3.011. El ejemplar fue regalado a Menéndez Pelayo por su dueño, el Duque de T'Serclaes y no por su hermano, el Marqués de Jerez de los Caballeros, como dice Cotarelo. En la Biblioteca Nacional de Madrid hay una fotocopia de esta égloga: R. 22.620. Simón, Bibliografia, III, 4.696. Está encuadernada en pasta española con sello dorado de la Biblioteca Nacional en el ángulo superior derecho de la tapa delantera, y en el inferior izquierdo de la posterior. En el lomo, tejuelo rojo con letras doradas: ENCINA/ ÉGLOGA. El encuadernador ha colocado una guarda antes y otra después del texto fotocopiado. En la Biblioteca de Menéndez Pelayo no hay ningún ejemplar de la suelta de la llamada Égloga del Amor. Quien dio la noticia por primera vez se dejó engañar por una ficha de la Biblioteca que contiene el Diálogo del Amor de Iuan de Enzinas (R-IV-B, 1.078), pero este autor no es nuestro salmantino. El frontis del ejemplar lee así: DIALOGO/ DE AMOR/ INTITULADO DORIDA/ En que se trata de las causas por donde puede/ justamente un amante (sin ser notado/ de inconstante) retirarse de su amor. Nueuamente sacado a luz, corregido y/ enmendado por Iuan de Enzi/ nas, vezino de Burgos. CON PRIVILEGIO/ EN BURGOS/ En la imprimería de Philippe de Iunta y Iuan Baptista Varesio/ 1593. 
En la contraportada hay un ex libris de Roberti Samuelis Turner en el borde superior, hacia el centro, y en el medio, ex libris del Duque de T'Serclaes de Tilly. Inmediatamente debajo, la firma de don Marcelino Menéndez Pelayo. Está bellamente encuadernado en piel castaña con marcos dorados y otros grabados en madera sobre la piel de las tapas. En la tapa anterior, con letras doradas: ROMANCE| DE DON GAYFEROS, ROMANCE DE| CALISTO Y MELIBEA, y EGLOGA| NUEUAMENTE TROBADA| POR JUAN DEL ENZINA. Lomo con cinco nervios y adornos dorados sobre ellos. En la parte inferior del lomo, tejuelo con la signatura.

Égloga XII. Égloga de Fileno y Zambardo ${ }^{66}$.

A. ¿Alcalá de Henares, c. $1511 ?^{67}$

El ejemplar que perteneció a Fernando Colón se ha perdido.

${ }^{66}$ De esta égloga solo se conservan dos ejemplares correspondientes a sendas ediciones de principios del siglo XVI. (Vid. infra, B y C). Entre 1870 y 1880 D. José Sancho Rayón preparó unas curiosísimas reproducciones de las Coplas de Zambardo y del Auto del repelón. Ambas copias fueron hechas sobre el texto de la edición salmantina del Cancionero de 1509. No se trata de una simple reproducción fotográfica: el autor redividió el texto para adaptarlo al formato de cuarto e inventó varios detalles ornamentales tomados de otros libros editados por el mismo Gysser. Norton, Printing, pág. 29, había advertido ya del asunto, ante el hecho de que algunos estudiosos tenían por auténticas estas reproducciones, concretamente el ejemplar de Madrid (Biblioteca Nacional, $\mathrm{C}^{\text {a }} 266$, v. 36) de las Coplas de Zambardo y el de Barcelona (Biblioteca de Catalunya (Bon 7-V-54/ R. 188.690) del Auto del repelón. Más tarde, respondiendo a algunas de mis dudas sobre el particular, escribió: "As for the quarto editions of the Coplas de Zambardo and the Auto del repelón my opinion remains unchanged. The copies in Madrid and Barcelona are not originals but photographic artifacts derived from the folio 1509 printing of the Cancionero and made by José Sancho Rayón in Madrid c. 1870-80 [...] If you will compare one of them with the 1509 folio I think you will agree it is an exact reproduction redivided to fit into quarto format. The title-page of the Zambardo has its decorative elements photographed from various books printed by Gysser and is an invention of Sancho Rayón's, made I believe as an experiment and not with any intention of deceive". Con anterioridad a Mr. Norton, ya varios estudiosos habían mencionado estas reproducciones fotográficas, entre ellos, Vindel, Manual, III, no. 871, que dice: "De ella [la versión de las Coplas de la edición salmantina de 1509] se hizo una reproducción facsimilar, hoy escasa, pero de la que conserva un ejemplar la Biblioteca Nacional V-Ca, 266, no. 36, procedente de la biblioteca de Gayangos, y otro de la de Menéndez y Pelayo, de Santander, R-VI-5-9". Vid. Cuesta, Salamanca, pág. 126; Simón, Bibliografia, III, no. 4685. El ejemplar madrileño, cuya signatura de los pliegos es $a^{8}+b^{6}$ ( = portada +13 hojas de texto, s.n.), lleva en la portada un sello acuñado en tinta roja que dice: "Pascual de Gayangos". Los pliegos no están encuadernados, sino protegido por unas tapas de papel verde grueso sujetas a los pliegos por tres grapas. Sobre la tapa delantera, con lápiz rojo, $C^{a} 266$ v 36. Todavía se conserva la signatura de Gayangos: G 14.243.

${ }^{67}$ Cf. Norton, Catalogue, no. 1347. El bibliófilo inglés cree que el impresor de esta obra pudo haber sido Brocar, y el lugar de impresión, Logroño o la misma Alcalá de Henares; cree, además, que en esa misma ocasión Hernando Colón compró también otras piezas para su biblioteca: la Historia de los tres reyes magos (3859 del Registrum), la Cárcel de amor de Diego de San Pedro, con una continuación de Nicolás Núñez (30006) y un Sermón del mismo San Pedro (3856). Vid. los nos. 395, 396 y 11 del Catalogue, respectivamente. 
$\mathrm{B}^{68}$

Portada: No tiene. Encabeza la primera hoja un grabado con cuatro figurillas, tres pastores y una pastora, que representan a los personajes de la égloga, todos enmarcados por una orla estrecha. Debajo, la introducción: Egloga trobada por| Juan del Enzina, en la qual se introduzen tres pastores| Fileno, Zambardo, Cardonio. Donde se recuenta cómo| este Fileno, preso de amor por vna muger llamada Zefira| de cuyos amores viéndose muy desfauorecido, cuenta| su pena a Zambardo y a Cardonio. El qual no hallan| do en ellos remedio, por sus propias manos se mató.

Formato: [12] h.-Sign.: $\mathrm{a}^{12} \cdot-4 .^{\circ} \mathrm{L}$. gót.

Contenido: Texto en prosa (la introducción) y en verso a una columna. Primer verso: Descansar yo quiero en aqueste prado; último: vn triste réquiem que diga de amores.

Colofón: No tiene.

Ejemplares:

\section{Biblioteca Nacional, Madrid, R-4993}

Ejemplar completo. Está encuadernado en piel castaña; en las tapas, grabados en madera de cuadrados y un rombo en el medio. Grabado de hierro dorado a lo largo del lomo: ENZINA, EGLOGA DE LOS TRES PASTORES.

$C^{69}$

Portada: No tiene. En la primera plana, cuatro figuras humanas con los letreros: Fileno, Zambardo, Cardonio y Zefira; debajo, el título: Égloga de los tres pastores nueuamente trobada por Juan del enzina.

Formato: [12] h.-Sign.: $\mathrm{a}^{12} .-4 .^{\circ} \mathrm{L}$. gót.

Contenido: Texto en prosa (la introducción) y en verso a una columna.

Primer verso: Descansar yo quiero en aqueste prado; último: vn triste réquiem que diga de amores:

Colofón: No tiene.

${ }^{68}$ Salvá, Catálogo, 1.228: Graësse, Trésor, II, pág. 473; Palau, V, pág. 52, no. 79.585; Simón, Bibliografia, III, no. 4.307; Faulhaber, Bibliography, pág. 182, no. 2.148. Hay notables diferencias gráficas y de lectura entre este texto y el del Cancionero de 1509, entre ellas, la adición de dos grupos estróficos al principio y otros dos al final.

${ }^{69}$ Salvá, Catálogo, 1.288; Catalogue général, Vol. XXIV, pág. 394; Álvarez, Repelón, pág. 186; Cotarelo, "Prólogo", pág. 24; Graësse, Trésor, II, pág. 473; Simón, Bibliografia, III, 4.687; Faulhaber, Bibliography, pág. 217 , no. 2.621 . 
Ejemplares:

1. Bibliothèque Nationale, Paris. Rés. Yg. 86

Ejemplar completo.

D. Toledo, en casa de Juan de Ayala, en cuarto, h. $1553^{70}$.

Égloga XIII. Auto del repelón.

Ejemplares: No se conocen $^{71}$.

Égloga XIV. Égloga de Plácida y.Vitoriano.

A. Roma, $1514^{72}$

Ejemplares: No se conocen ${ }^{73}$.

B

Portada: No tiene. La primera página comienza con un grabado; fuera de una sencilla orla de dos líneas, en la parte superior, los nombres Plácida y

${ }^{70} \mathrm{La}$ información sobre la existencia de esta edición apareció por primera vez en la versión española de la History of the Spanish Literature de J. Ticknor, como un añadido de los traductores; Cf. la pág. 529 del vol. I. Tras ellos, la citan algunos estudiosos, pero nadie ha visto ejemplares. Vid. Cristóbal Pérez Pastor, La imprenta en Toledo, Descripción bibliográfica de las obras impresas en la imperial ciudad desde 1483 hasta nuestros días, Madrid, Imprenta de M. Tello, 1887, vol. I, pág. 266; Álvarez, Repelón, pág. 186; Simón, Bibliografia, III, 4.694.

${ }^{71}$ Algunos estudiosos suponen que existió una edición suelta antigua del Auto, pero nadie ha visto más ejemplar que la 'edición' fotográfica de José Sancho Rayón, hecha sobre papel de hilo. Vid. Cotarelo, "Prólogo", págs. 22-23; Cuesta, Salamanca, pág. 125; Simón, Bibliografia, III, 4.673. El ejemplar de Barcelona, que es el que conozco, pudiera pasar con facilidad como auténtico a ojos poco expertos: la signatura del pliego es: $\mathrm{a}^{10}=10$ hojas numeradas de texto. Hay un error en la signatura del pliego: $a^{2}$ va entre $a^{4}$ y $^{5}$, y $\left[a^{9}\right]$. entre $\left[a^{6}\right]$ y $\left[a^{7}\right]$. El error se traspasa a la numeración: $[1], 3,4,2,5,6,9,7,8,10$. Todas llevan la abreviatura fo. antes el número. El pliego no está encuadernado ni tiene cubiertas; cuando llegó a mis manos estaba intonso. Hay sellos de la Biblioteca Central en las hojas $1,5, \mathrm{r}$ y 10,v. Al final del vuelto de la 10 hay un pequeño papel pegado con la signatura, repetida en tinta y a lápiz sobre el papel del ejemplar mismo; además, el número de clasificación: 834.6 "15" Sut.

${ }^{72}$ Posiblemente fuera un ejemplar de esta edición el que vio Juan de Valdés, Diálogo de la lengua (ed. de Rafael Lapesa, Zaragoza: Clásicos Ebro, 1960), pág. 106: "lo que me contenta más es la farsa de Pláçida y Vitoriano que compuso en Roma". Aunque varios estudiosos citan esta edición, nadie ha visto ejemplares. Vid. Moratín, Orígenes, pág. 68; Brunet, Manuel II, págs. 972; Barrera, Catálogo, pág. 131: Graësse, Trésor, II, pág. 473; Enrico Zaccaria, Bibliografia Italo-Spagnuola, ossia edizione e versione di opere spagnuole e portoghesi fattese in Italia, segunda edición, Capri, Tip. Ravagli, 1908, pág. 12.

${ }_{73}$ Se ha perdido el ejemplar que Hernando Colón compró en Medina en 1524 (Registrun, 4044). Cañete, "Prohemio", pág. xiii, nota 1, recuerda que esta égloga fue prohibida por la Inquisición, no sabemos desde cuándo, pero ya aparece en el Indice expurgatorio de 1559; son varios los autores que atribuyen a este hecho el que no se haya conservado ejemplar alguno de esta supuesta primera edición. Vid. Palau, V, pág. 52. 
Vitoriano. Debajo de cada nombre, las figuras correspondientes, "ella con ropa larga, y larga toca que levanta el viento, y en actitud de hablar, y él, con sombrero de plumas, afectado y con largo cabello hasta los hombros; capa muy corta y bastón; en medio de ellos, un árbol; a la izquierda una casa y a la derecha más árboles, uno con un pájaro". Debajo, la introducción: Égloga nueuamente trobada por| juan d'l enzina. En la qual se intro| duzen dos enamorados llamada| ella Plácida y él Uitoriano. Ago| ra nueuamente enmendada y añadido| vn argumento siquier introdución| de toda la obra en coplas: y más ol tras doze coplas que faltauan en las| otras que de antes eran impresas.| con el Nunc dimittis trobado por| el bachiller Fernando de yanguas.

Formato: [20] h.-Sign.: $a-b^{8} c^{4} \cdot 4 .^{\circ}$ L. gót.

Contenido: Texto en prosa (la introducción) y en verso, este a dos columnas. Primer verso: Dios salue, compaña nobre; último: Soy contenta y muy de grado.

Colofón: No tiene [Burgos, Alonso de Melgar, c. 1518-1520?].

Ejemplares:

\section{Biblioteca Nacional, Madrid, R-4888}

Ejemplar completo. Debajo de la primera página, un sello de la Biblioteca Nacional. Encuadernado en piel; en el centro de las tapas, el sello de Salvá grabado en hierro dorado. Lomo cuajado con cuatro nervios. En el lomo: PLACIDA| Y| VICTORI| ANO, y más abajo: S. L.| NI $A^{74}$.

C

Portada: Égloga delos dos enamora/ dos Plácida y Uictoriano [sic]. Agora nueuamente corregida y emendada. Sobre el título, grabado en madera que ocupa casi toda la página; las figuras de Plácida y Vitoriano en un interior, al fondo, una ventana. El grabado y el título están enmarcados por una orla irregular.

Formato: [23] h.-Sign.: [ $]^{1} a-b^{12} \cdot 4 .^{o}$ L. gót.

74 Gallardo, Ensayo, 2.074; Salvá, Catálogo, 1.227, quien, basado en ciertos detalles del grabado, supuso que había sido impresa en Burgos por Alonso de Melgar (h. 1520); el Catalogue de la Bibliothèque de M. Heredia, II, 2.310, repite a Salvá (Burgos, h. 1520); Álvarez, Repelón, pág. 196; Cotarelo, "Prólogo", págs. 26-27: Simón, 'Bibliografia, III, 4.693; Antonio Rodríguez Moñino, Diccionario bibliográfico de pliegos sueltos poéticos (siglo XVI), Madrid, 1970; Norton, Catalogue, no. 331. Todos describen el ejemplar de Salvá, que trae varias canciones tras el texto de la égloga; la última estrofa anuncia el Nunc dimittis, que sigue a continuación. Existe edición facsímil en Autos, comedias y farsas de la Biblioteca Nacional, Madrid, Joyas Bibliográficas, 1964, vol. I, 241-280. 
Contenido: Portada + texto en prosa (la introducción) y en verso, este a dos columnas. Primer verso: Dios salue, compaña nobre; último: Soy contenta y muy de grado.

Colofón: No tiene.

Ejemplares:

\section{Bibliothèque de L'Arsenal, Paris, Rés. $4 .^{\circ} \mathrm{BL} 4088(2)^{75}$}

A este ejemplar le faltan las primeras once coplas, con todo el Introito, y al final, cuatro quintillas. Después de las palabras "Fin de las coplas", no aparece el Nunc dimittis.

En el lado inferior de la orla que adorna la portada, en medio de la barra, se lee IHS. En el ángulo inferior derecho hay un sello de la Bibliothèque de L'Arsenal, y entre paréntesis, a mano, un número 2. Todo el tomito donde se encuentra esta égloga tiene las páginas numeradas a mano, hasta un total de 96.

\section{FINAL}

El presente trabajo ha sido realizado a lo largo de varios años. Las visitas que he podido hacer a varias bibliotecas que guardan en sus anaqueles ediciones antiguas de las églogas de Encina han sido ocasionales, cuando otras actividades me lo permitían. Se trata de una investigación varias veces interrumpida, debido a requerimientos más apremiantes. Creo haber consignado en estas páginas, sin embargo, todos los ejemplares hoy conocidos, pero en cuestiones bibliográficas nunca se dice la última palabra. Espero que estas páginas ayuden a los que emprendan trabajos sobre el padre de nuestro teatro.

En esta última etapa de poner a punto los viejos y nuevos materiales para rendir homenaje a mi maestro, D. Rafael Lapesa, he contado con dos colaboraciones inapreciables, la de Julián Martín Abad, Jefe de Servicios de Manuscritos, Incunables y Raros de la Biblioteca Nacional de Madrid, y la de María Luz González López, Bibliotecaria de la Real Academia Española. Ambos han leído el manuscrito de este trabajo, y con sus atinadas observaciones y consejos han conseguido evitar errores y mejorar notablemente el texto. A ellos, mi más sincera gratitud.

${ }^{75}$ Aliprandini, Triunfo del amor, Égloga de Plácida y Vitoriano, pág. 25, reproduce la portada de este ejemplar; cf., además, sus págs. 47-48. 